Supporting Information for

\title{
Synthesis of Benzobisoxazole-Linked Two-Dimensional Covalent Organic Frameworks and Their Carbon Dioxide Capture Properties
}

DAVID A. PYLES, JONATHAN W. CROWE, LUKE A. BALDWIN, PSARAS L. MCGRIER*

Department of Chemistry \& Biochemistry, The Ohio State University, Columbus, Ohio, 43210

Table of Contents

\begin{tabular}{|c|c|c|}
\hline A. & Materials & $\mathrm{S} 2$ \\
\hline B. & Instrumentation and Methods & $\mathrm{S} 2$ \\
\hline C. & Synthetic Methods & $\mathrm{S} 3$ \\
\hline D. & FT-IR Spectra & $\mathrm{S} 5$ \\
\hline E. & $\begin{array}{c}\text { Experimental \& Pawley Refined } \\
\text { PXRD Profiles }\end{array}$ & $\mathrm{S} 8$ \\
\hline F. & $\begin{array}{c}\text { Solid State NMR Spectra } \\
\text { TGA Profiles }\end{array}$ & $\mathrm{S} 13$ \\
\hline G. & S14 \\
\hline H. & $\begin{array}{c}\text { BET Surface Area Plots \& Pore } \\
\text { Volume Calculations }\end{array}$ & $\mathrm{S} 15$ \\
\hline I. & $\begin{array}{c}\text { Isoteric Heat of Adsorption Plots } \\
\text { J. }\end{array}$ & $\mathrm{S} 16$ \\
\hline K. & Selectivity Plots & $\mathrm{S} 17$ \\
\hline L. & WEM Micrographs & $\mathrm{S} 19$ \\
\hline M. & $\begin{array}{c}{ }^{1} \mathrm{H} \text { and }{ }^{13} \text { C NMR Spectra of BBO-1 } \\
\text { Water Stability Plot }\end{array}$ & $\mathrm{S} 21$ \\
\hline
\end{tabular}




\section{A. Materials}

Unless stated otherwise all reagents were purchased from commercial sources and used without further purification. Dimethylformamide was purified by passage over activated alumina.

\section{B. Materials, Instrumentation and Methods}

Infrared spectra were recorded on a Thermo Scientific Nicolet iS5 with an iD7 diamond ATR attachment and are uncorrected.

X-ray diffraction patterns were recorded on a Bruker D8 Powder X-Ray Diffractometer employing $\mathrm{Cu} \mathrm{K}(\mathrm{a})^{1}$ line focused irradiation at $40 \mathrm{kV}, 50 \mathrm{~mA}$ power and equipped with a $\mathrm{Ge}$ (111) monochromator. Samples were mounted on a zero background sample holder by dropping powders from a vial and then flattening them by firmly pressing the sample with a wide-blade spatula. No sample grinding was used prior to analysis. The holder was then placed on the mounting apparatus in the diffractometer. Data was collected after a 12 minutes delay time using a $0.015^{\circ} 2 \theta$ step scan from $1-34^{\circ}$ with an exposure time of $2-3$ sec per step.

Solid-state ${ }^{13} \mathrm{C}$ NMR spectra for BBO-COF 1 and BBO-COF 2 were recorded using a Bruker DPX $300 \mathrm{MHz}$ spectrometer using a Bruker magic angle spinning (MAS) probe and running $32 \mathrm{k}$ scans. Cross-polarization with MAS (CPMAS) was used to acquire ${ }^{13} \mathrm{C}$ data at $75.5 \mathrm{MHz}$. The $\mathrm{CP}$ contact time was $2 \mathrm{~ms}$ at $50 \mathrm{kHz}$ for ${ }^{1} \mathrm{H}-{ }^{1} \mathrm{H}$. ${ }^{1} \mathrm{H}$ decoupling was applied during data acquisition. The decoupling power corresponded to $100 \mathrm{kHz}$. The MAS sample spinning rate was $10 \mathrm{kHz}$.

Thermogravimetric analyses (TGA) were carried out using a Perkin-Elmer thermal gravimetric analyzer 7 by heating samples in a platinum pan from $20{ }^{\circ} \mathrm{C}$ to $1000{ }^{\circ} \mathrm{C}$ under nitrogen atmosphere at a heating rate of $10^{\circ} \mathrm{C} \mathrm{min}{ }^{-1}$ without an equilibration delay.

Surface area measurements were conducted on a Micromeritics ASAP 2020 Surface Area and Porosity Analyzer using ca. 20-100 mg samples. Nitrogen isotherms were generated by incremental exposure to ultra high purity nitrogen up to ca. $1 \mathrm{~atm}$ in a liquid nitrogen $(77 \mathrm{~K}) \mathrm{bath}$. Carbon dioxide isotherms were generated by ultra-high purity carbon dioxide to ca. $900 \mathrm{mmHg}$ in a water $(295 \mathrm{~K})$ bath and an ice $(273 \mathrm{~K})$ bath. Surface parameters were determined using BET adsorption models in the instrument software. The pore size distributions were measured using the non-local density functional theory (NLDFT) model (cylinder pore, $\mathrm{N}_{2}$-cylindrical poresoxide surface) with the instrument software (Micromeritics ASAP 2020 V4. 02).

Selectivity calculations were conducted using initial slope calculations from $\mathrm{N}_{2}$ and $\mathrm{CO}_{2}$ isotherms taken at both $273 \mathrm{~K}$ and $295 \mathrm{~K}$.

Scanning electron microscopy (SEM) was performed on a FEI sirion FE-SEM. Materials were deposited onto a film of wet colloidal silver paint on an aluminum sample stub and dried in a vacuum oven at $40{ }^{\circ} \mathrm{C}$. The samples were coated with gold in a Leica EM ACE600 coater, using rotation, to a depth of approximately $20 \mathrm{~nm}$. After coating the samples were imaged in the SEM at $5 \mathrm{keV}$, without tilting, using both the secondary electron (SE) detector and the through lens detector (TLD). 
Elemental analysis was performed by Galbraith Laboratories using a Thermo Finnigan FlashEA 1112 Elemental Analyzer.

Water stability testing was conducted by soaking the polymers in water at room temperature for one day, and a second day at $100^{\circ} \mathrm{C}$. BET adsorption isotherms were remeasured to determine stability.

\section{Synthetic Methods}

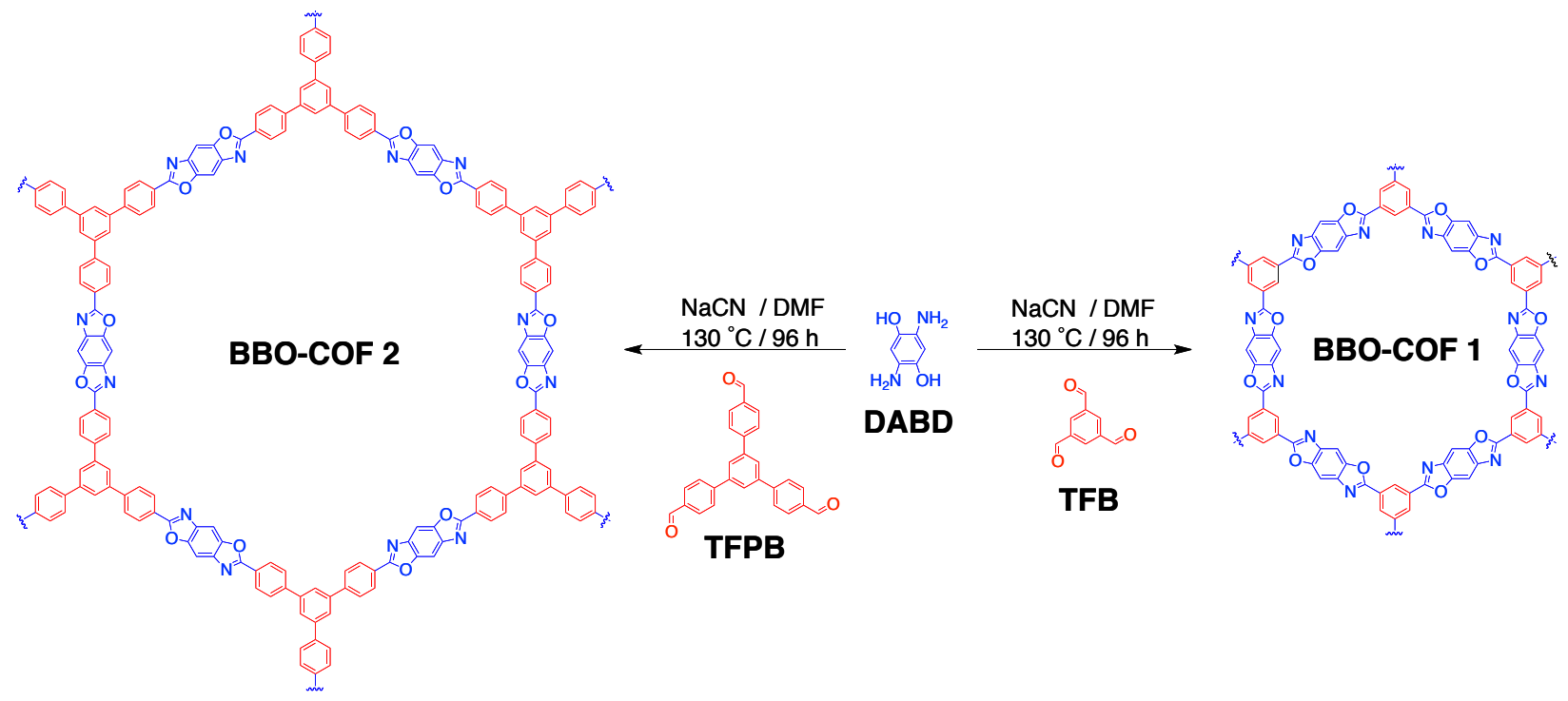

Scheme 1. Synthesis of BBO-COF 1 and BBO-COF 2.

2,5-Diamino-1,4-benzenediol bis hydrochloride (DABD): This compound was prepared using procedures adapted from Strom and Jeffries-EL et al. ${ }^{1,2}$

1,3,5-Triformylbenzene (TFB): This compound was prepared using a procedure from Phanstiel IV et al. $^{3}$

1,3,5-Tris(4-formylphenyl)benzene (TFPB): This compound was prepared using a procedure from Cooper et al. ${ }^{4}$

BBO-COF 1: 2,5-Diamino-1,4-benzenediol dihydrochloride (31.9 mg, $0.15 \mathrm{mmol}, 1.5$ equiv.) was added in DMF $(5 \mathrm{~mL})$ under a $\mathrm{N}_{2}$ atmosphere. The solution was cooled to $-15{ }^{\circ} \mathrm{C}$ (ethylene glycol/ $\mathrm{CO}_{2}$ ) and 1,3,5-triformylbenzene (16.2 $\mathrm{mg}, 0.10 \mathrm{mmol}, 1$ equiv.) in DMF (5 mL) was added to the solution over 20 minutes. The solution was stirred at $-15{ }^{\circ} \mathrm{C}$ for an additional 3 hours before warming to room temperature in a water bath overnight. The reaction was put under air, and sodium cyanide $(4.9 \mathrm{mg}, 0.10 \mathrm{mmol}, 0.33$ equiv. per aldehyde) was dissolved in methanol $(0.2 \mathrm{~mL})$ before adding it into the solution. The reaction was heated to $130{ }^{\circ} \mathrm{C}$ for 96 hours before filtering, washing with acetone. The solids were soaked in methanol for 24 hours, changing out the solvent 3 times over that period. An addition soak was performed in acetone, 
following the same procedure. The solids were filtered and dried under vacuum for a few hours before characterization leaving a light brown solid (30.1 mg, $97 \%$ ). FT-IR (powder, ATR): 1651, $1557,1418,1363,1258,1118,942,876,845,702 \mathrm{~cm}^{-1}$. CP/MAS ${ }^{13} \mathrm{C}$ NMR $(75.5 \mathrm{MHz}, \delta \mathrm{ppm})$ : 161.0, 147.9, 140.0, 127.5, 100.4. Elemental Analysis for $\left(\mathrm{C}_{6} \mathrm{H}_{2} \mathrm{NO}\right)_{\mathrm{n}}$ : Calculated: $\mathrm{C}(69.23), \mathrm{H}$ (1.94), N (13.46); Observed: C (56.32), H (3.99), N (12.22).

BBO-COF 2: 2,5-Diamino-1,4-benzenediol dihydrochloride (95.7 mg, $0.45 \mathrm{mmol}, 1.5$ equiv.) was added in DMF $\left(15 \mathrm{~mL}\right.$ ) under a $\mathrm{N}_{2}$ atmosphere. The solution was cooled to $-15^{\circ} \mathrm{C}$ (ethylene glycol/ $\mathrm{CO}_{2}$ ) and 1,3,5-tris(4-formylphenyl)benzene (121.5 mg, $0.31 \mathrm{mmol}, 1$ equiv.) in DMF (15 $\mathrm{mL}$ ) was added to the solution over 20 minutes. The solution was stirred at $-15{ }^{\circ} \mathrm{C}$ for an additional 3 hours before warming to room temperature in a water bath overnight. The reaction was put under air, and sodium cyanide (15.2 $\mathrm{mg}, 0.31 \mathrm{mmol}, 0.33$ equiv. per aldehyde) was dissolved in methanol $(0.6 \mathrm{~mL})$ before adding it into the solution. The reaction was heated to $130{ }^{\circ} \mathrm{C}$ for 96 hours before filtering, washing with acetone. The solids were soaked in methanol for 24 hours, changing out the solvent 3 times over that period. An addition soak was performed in acetone, following the same procedure. The solids were filtered and dried under vacuum for a few hours before characterization leaving a light brown solid (102.8 mg, 62\%). FT-IR (powder, ATR): 1585, 1497, 1427, 1362, 1117, 1052, 1013, 832, 742, $696 \mathrm{~cm}^{-1}$. CP/MAS ${ }^{13} \mathrm{C}$ NMR $(75.5$ $\mathrm{MHz}, \delta \mathrm{ppm}): 164.4,141.1,127.7,101.7$. Elemental Analysis for $\left(\mathrm{C}_{12} \mathrm{H}_{6} \mathrm{NO}\right)_{n}$ : Calculated: C (79.99), H (3.36), N (7.77); Observed: C (70.48), H (4.21), N (7.65).

*In an effort to verify the formation of the benzoxazole linkage for the BBO-COFs, we also synthesized and characterized the following BBO analog 2,6-di-p-tolylbenzo[1,2-d:4,5d']bis(oxazole) (BBO-1) shown in Scheme 2.<smiles>Cc1ccc(C=O)cc1</smiles>
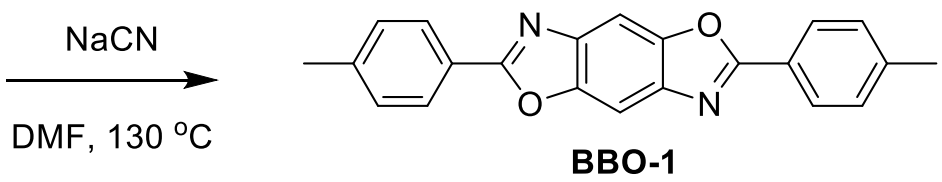

Scheme 2. Synthesis of BBO-1.

BBO-1: 2,5-Diamino-1,4-benzenediol dihydrochloride $(63.9 \mathrm{mg}, 0.30 \mathrm{mmol}, 0.5$ equiv.) was added in DMF $\left(5 \mathrm{~mL}\right.$ ) under a $\mathrm{N}_{2}$ atmosphere. The solution was cooled to $-15{ }^{\circ} \mathrm{C}$ (ethylene glycol $\left./ \mathrm{CO}_{2}\right)$ and $\mathrm{p}$-tolualdehyde $(0.07 \mathrm{~mL}, 0.6 \mathrm{mmol}, 1$ equiv.) was added to the solution over 20 minutes. The solution was stirred at $-15{ }^{\circ} \mathrm{C}$ for an additional 3 hours before warming to room temperature in a water bath overnight. The reaction was put under air, and sodium cyanide (29.4 mg, $0.6 \mathrm{mmol}, 1$ equiv.) was dissolved in methanol $(0.8 \mathrm{~mL})$ before adding it into the solution. The reaction was heated to $130{ }^{\circ} \mathrm{C}$ for 24 hours. The solution was cooled to room temperature and water was added which formed a precipitate. The precipitate was filtered and purified via recrystallization in toluene to afford the title compound, (BBO-1), as a yellowish/brown solid (54.8 mg, 54\%) ${ }^{1} \mathrm{H}-\mathrm{NMR}\left(\mathrm{CDCl}_{3}, 400 \mathrm{MHz}\right) \delta 8.17(\mathrm{~d}, 4 \mathrm{H}) ; 7.89(\mathrm{~s}, 2 \mathrm{H})$; 7.35 (d, 4H); 2.46 (s, 6H). ${ }^{13} \mathrm{C}-\mathrm{NMR}\left(\mathrm{CDCl}_{3}, 150 \mathrm{MHz}\right) .164 .6,148.6,142.4,140.5,129.9,127.7$, 124.4, 100.8, 21.8. FT-IR (powder, ATR) 3028, 2920, 1660, 1613, 1587, 1562, 1499, 1448, $1409,1366,1282,1213,1179,1117,1055,1017,919,870,817,731,720,689,638 \mathrm{~cm}^{-1}$. 


\section{FT-IR Spectra}

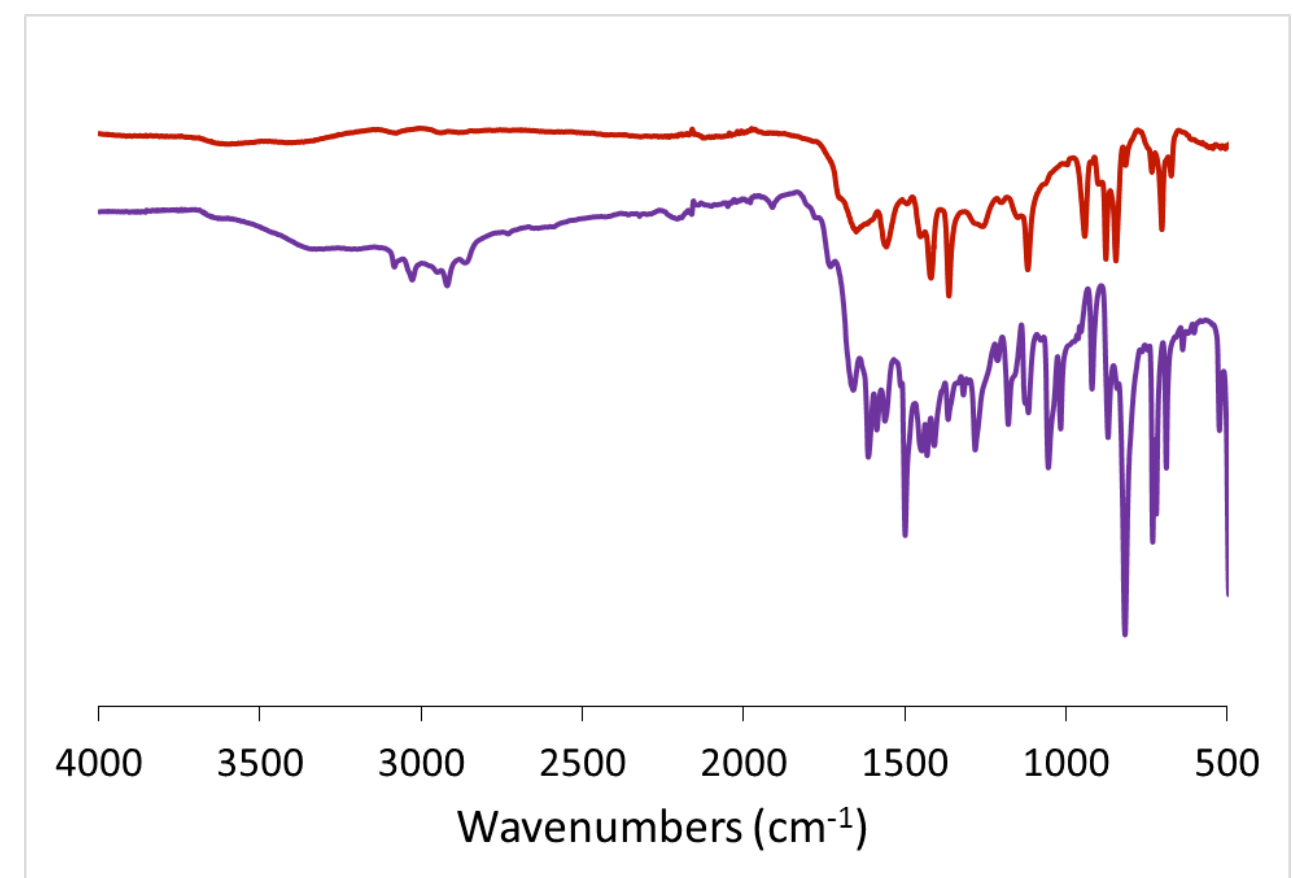

Figure S1. FT-IR of BBO-COF 1 (red) overlaid with BBO-1 (purple).

Table S1. FT-IR peak assignments for BBO-COF 1

\begin{tabular}{|c|c|}
\hline Peak $\left(\mathrm{cm}^{-1}\right)$ & Assignment \\
\hline 1651 & $\mathrm{C}=\mathrm{N}$ stretch of benzoxazole \\
\hline 1556 & $\mathrm{C}=\mathrm{C}$ stretch of benzene rings \\
\hline 1118 & C-O of benzoxazole \\
\hline
\end{tabular}




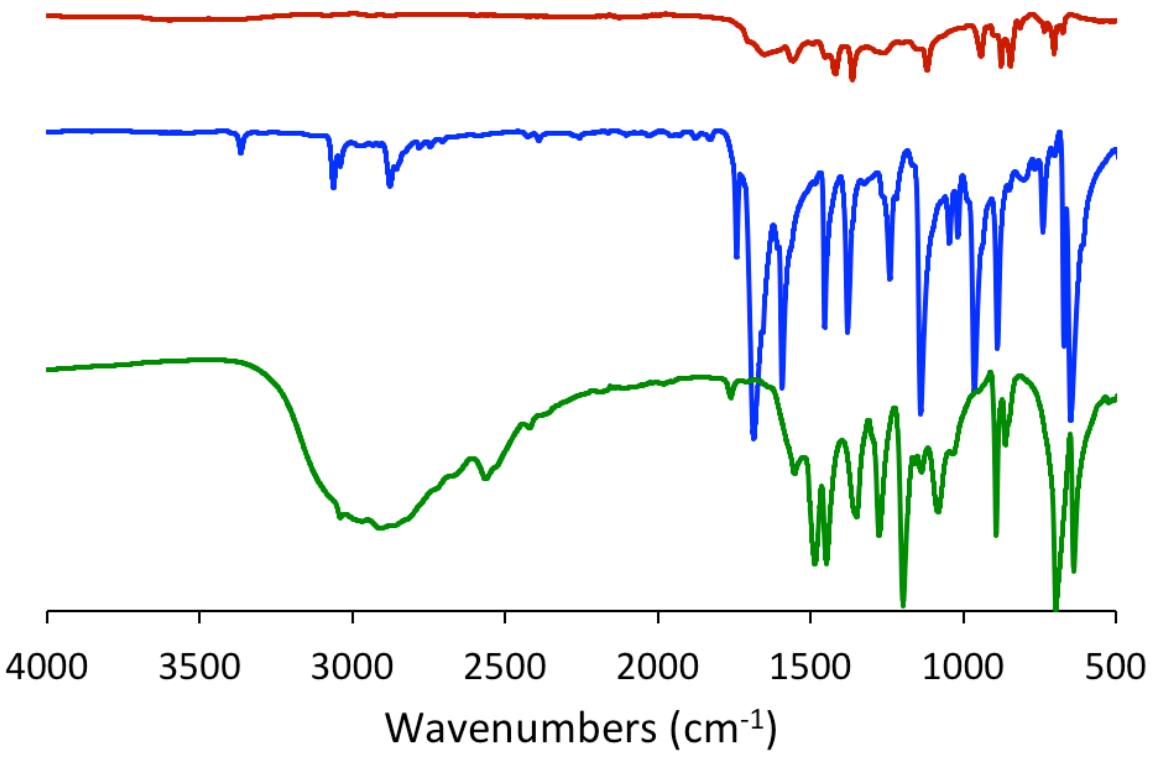

Figure S2. FT-IR of BBO-COF 1 (red) overlaid with TFB (blue) and DABD (green).

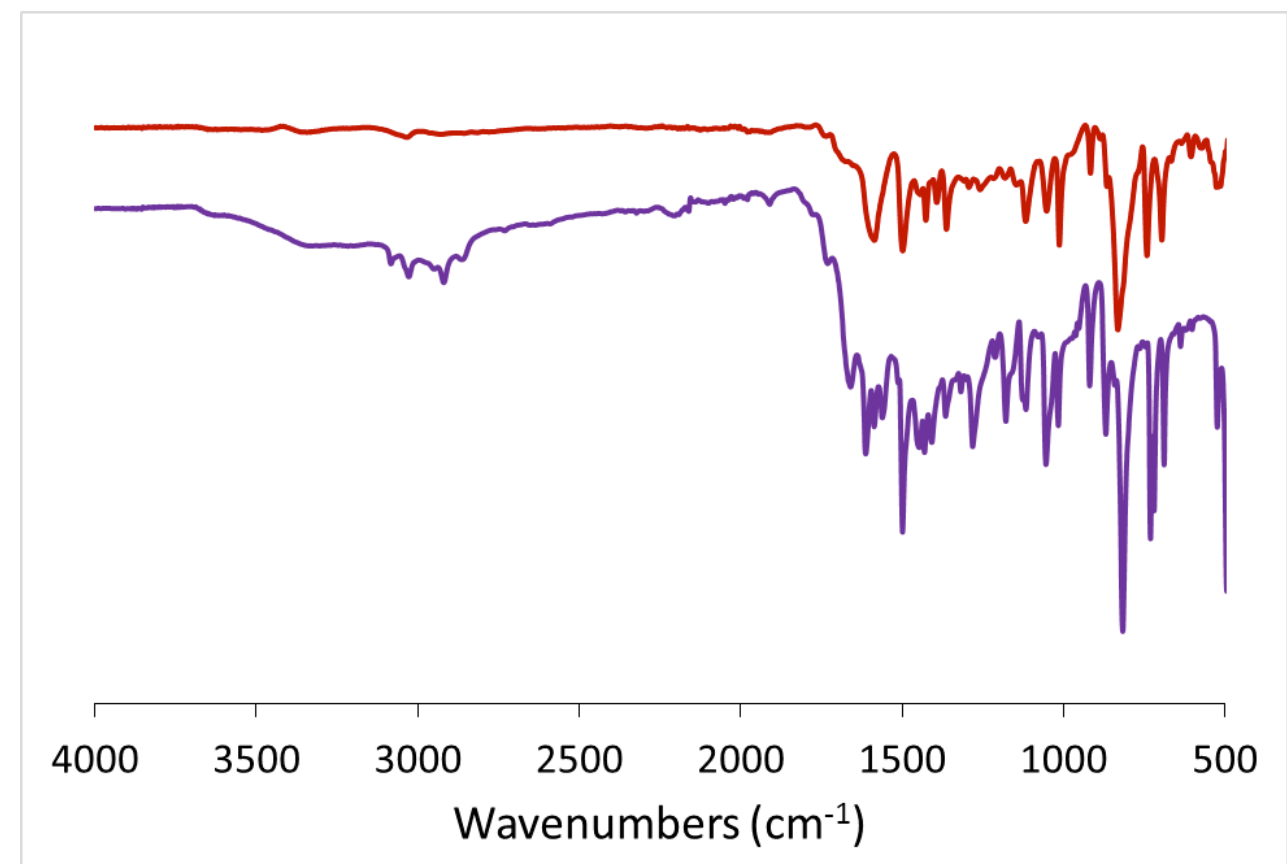

Figure S3. FT-IR of BBO-COF 2 (red) overlaid with BBO-1 (purple).

Table S2. FT-IR peak assignments for BBO-COF 2

\begin{tabular}{|c|c|}
\hline Peak $\left(\mathrm{cm}^{-1}\right)$ & Assignment \\
\hline 1642 & $\mathrm{C}=\mathrm{N}$ stretch of benzoxazole \\
\hline 1586 & C=C stretch of benzene rings \\
\hline 1117 & C-O of benzoxazole \\
\hline
\end{tabular}




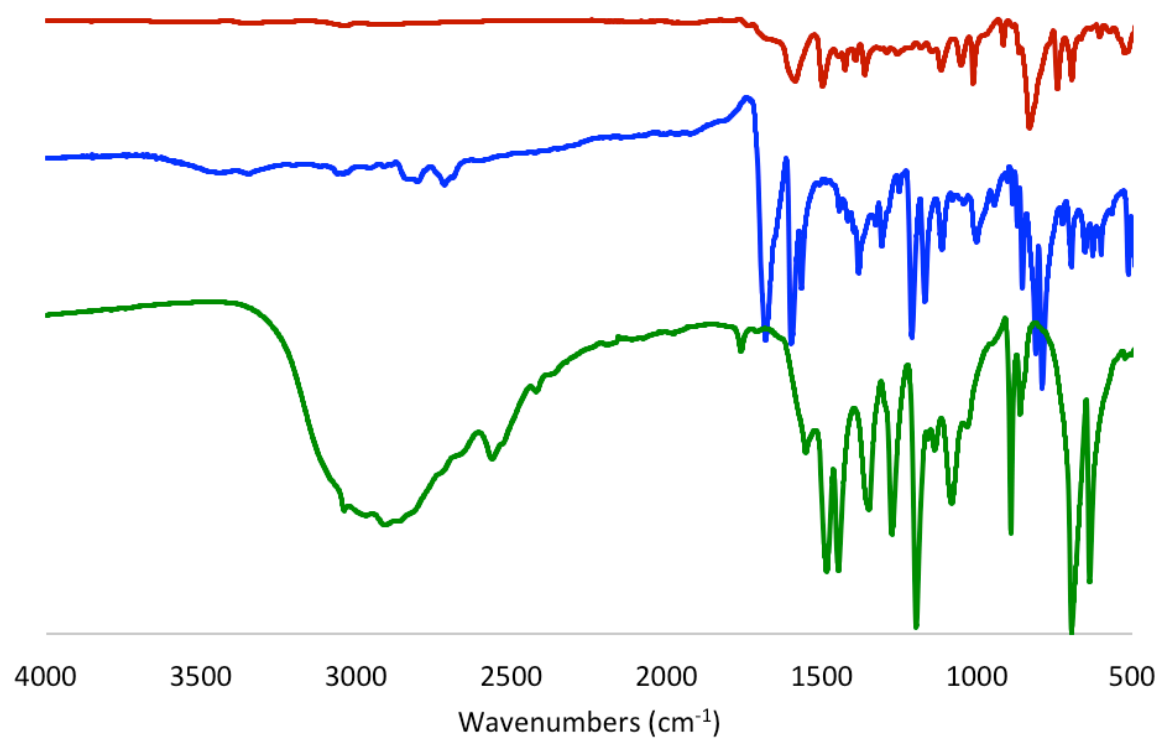

Figure S4. FT-IR of BBO-COF 2 (red) overlaid with TFPB (blue) and DABD (green). 


\section{E. Experimental \& Simulated PXRD Info}

The simulated PXRD profiles were performed using Materials Studio 7.0 using the unit cell precursors shown in Figure S3. Before the simulations were performed, each precursor was optimized using the geometry optimization task and Universal Forcefield parameters from the Forcite module. BBO-COF 1 and 2 were then modeled using a primitive hexagonal unit cell with a $P 6$ space group in which the stacking layers were offset by 5 and $15 \AA$, respectively. The $a=b$ parameters were estimated by measuring the distance between the BBO phenyl ring of the linkers for each COF. The c parameter was arbitrarily set at $3.4 \AA$. Models of BBO-COF 1 and BBO-COF 2 were also calculated using an eclipsed bnn $(\mathrm{P} 6 / \mathrm{mmm})$ hexagonal unit cell. The staggered molecular models were performed by offsetting the initial structures by half of the $a=b$ parameters using a gra $\left(\mathrm{P}_{3} / \mathrm{mmc}\right)$ space group and c parameter of $6.7 \AA$. Simulation of the possible structures was performed using Reflux Plus module to produce the expected PXRD profiles. The experimental PXRDs were then subjected to a Pawley refinement using PseudoVoigt peak shape function and Berar-Baldinozzi asymmetry correction function to produce the refined PXRD profile.

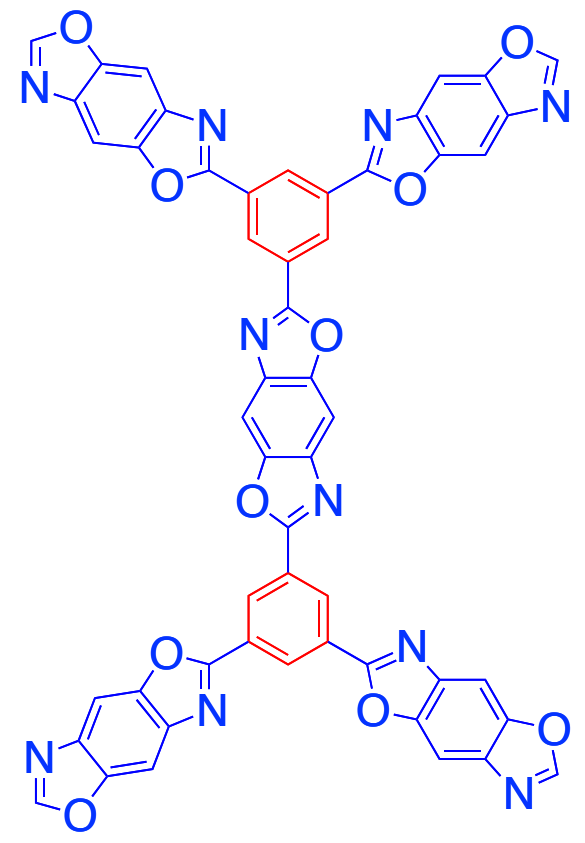

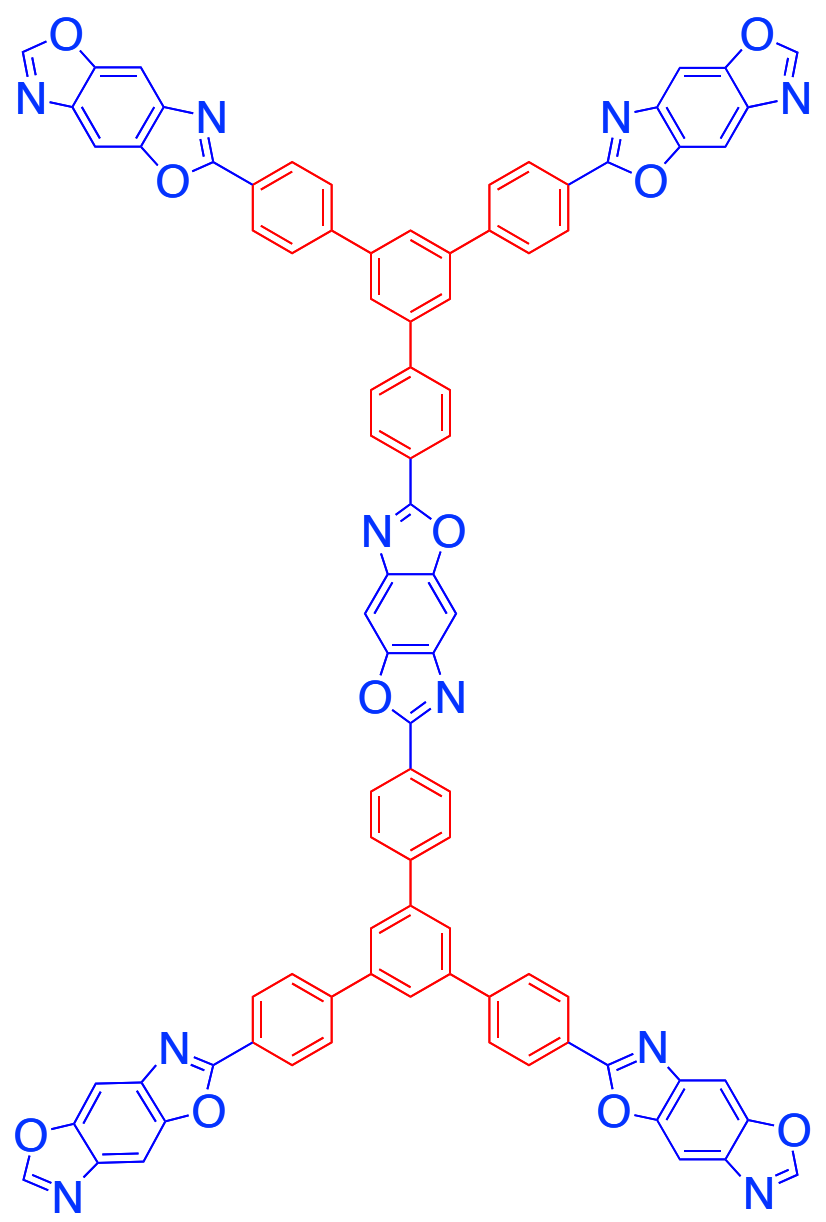

Figure S5. Precursors used to construct the hexagonal unit cells for BBO-COF 1 (left) and BBO-COF 2 (right). 


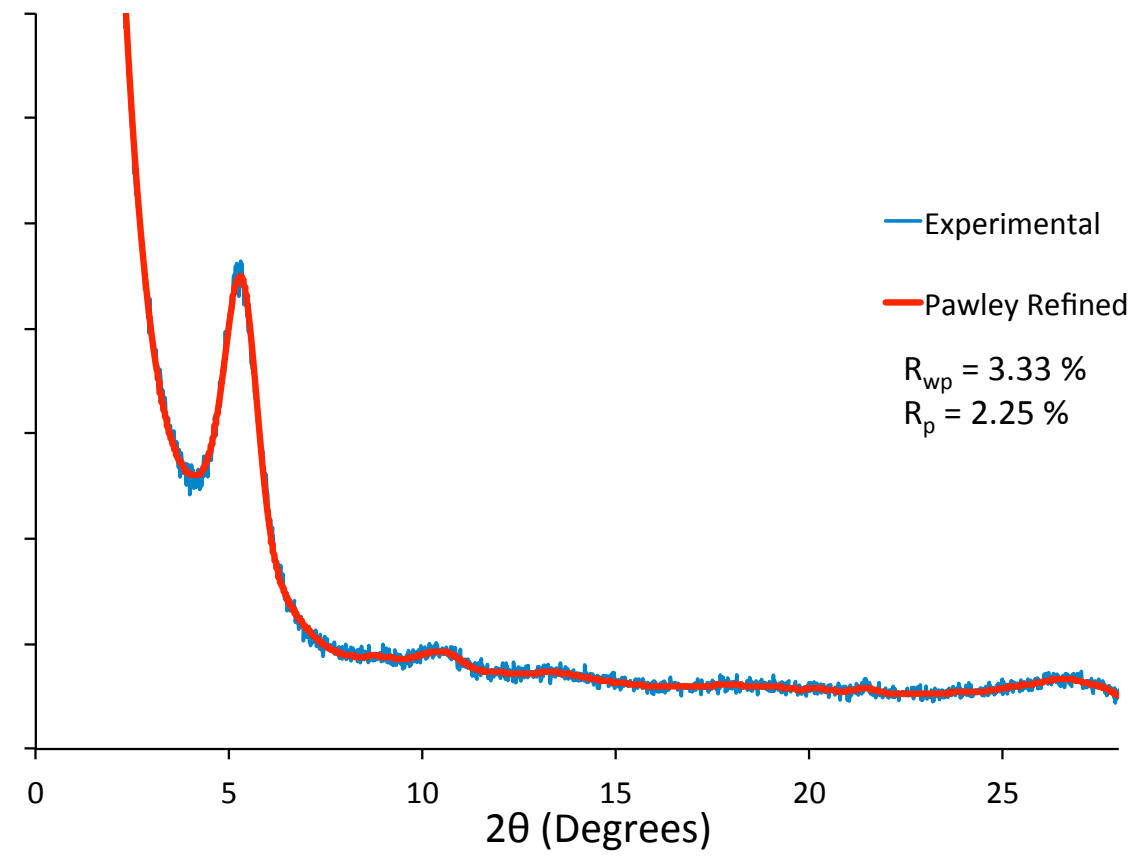

Figure S6. Experimental (red) and Pawley refined (blue) PXRD of BBO-COF 1.

Table S3. Fractional atomic coordinates for the bnn $(\mathrm{P} 6 / \mathrm{mmm})$ unit cell of BBO-COF 1 calculated using the Materials Studio 7.0.

\begin{tabular}{|cccc|}
\hline \multicolumn{4}{|c|}{ BBO-COF 1 } \\
\hline \multicolumn{4}{c|}{$\begin{array}{c}\text { Hexagonal, } \\
\mathrm{a}=\mathrm{b}=19 \text { space group }\end{array}$} \\
\hline Atom & $\mathbf{x}$ & $\mathbf{y}=3.4$ \\
C1 & 0.573707 & 0.956526 & $\mathbf{z}$ \\
C2 & 0.510764 & 0.901773 & 0.047838 \\
O3 & 0.497624 & 0.836925 & 0.047057 \\
C4 & 0.428192 & 0.800717 & 0.043042 \\
C5 & 0.390562 & 0.728052 & 0.040713 \\
C6 & 0.424051 & 0.692637 & 0.042499 \\
H7 & 0.490451 & 0.724910 & 0.046332 \\
C8 & 0.388956 & 0.623384 & 0.040323 \\
C9 & 0.423984 & 0.586015 & 0.042190 \\
N10 & 0.488346 & 0.615103 & 0.045901 \\
C11 & 0.500881 & 0.562227 & 0.046457 \\
C12 & 0.562180 & 0.565213 & 0.046457 \\
H13 & 0.621224 & 0.621058 & 0.053412 \\
C14 & 0.558848 & 0.503737 & 0.049562 \\
O15 & 0.610731 & 0.491258 & 0.052455 \\
& & & \\
\hline
\end{tabular}




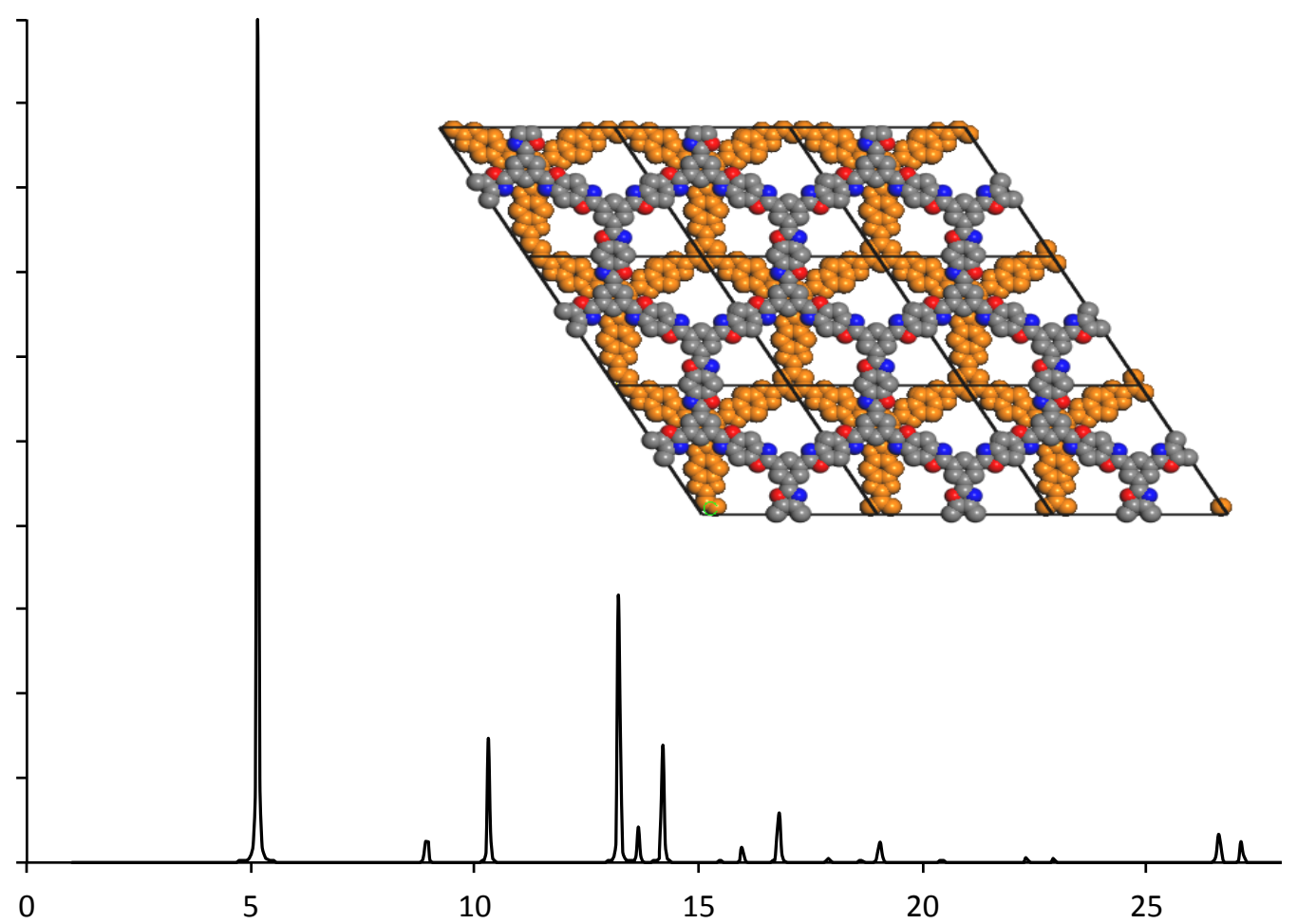

Figure S7. Simulated PXRD of BBO-COF 1 modeled using a gra unit cell (top right).

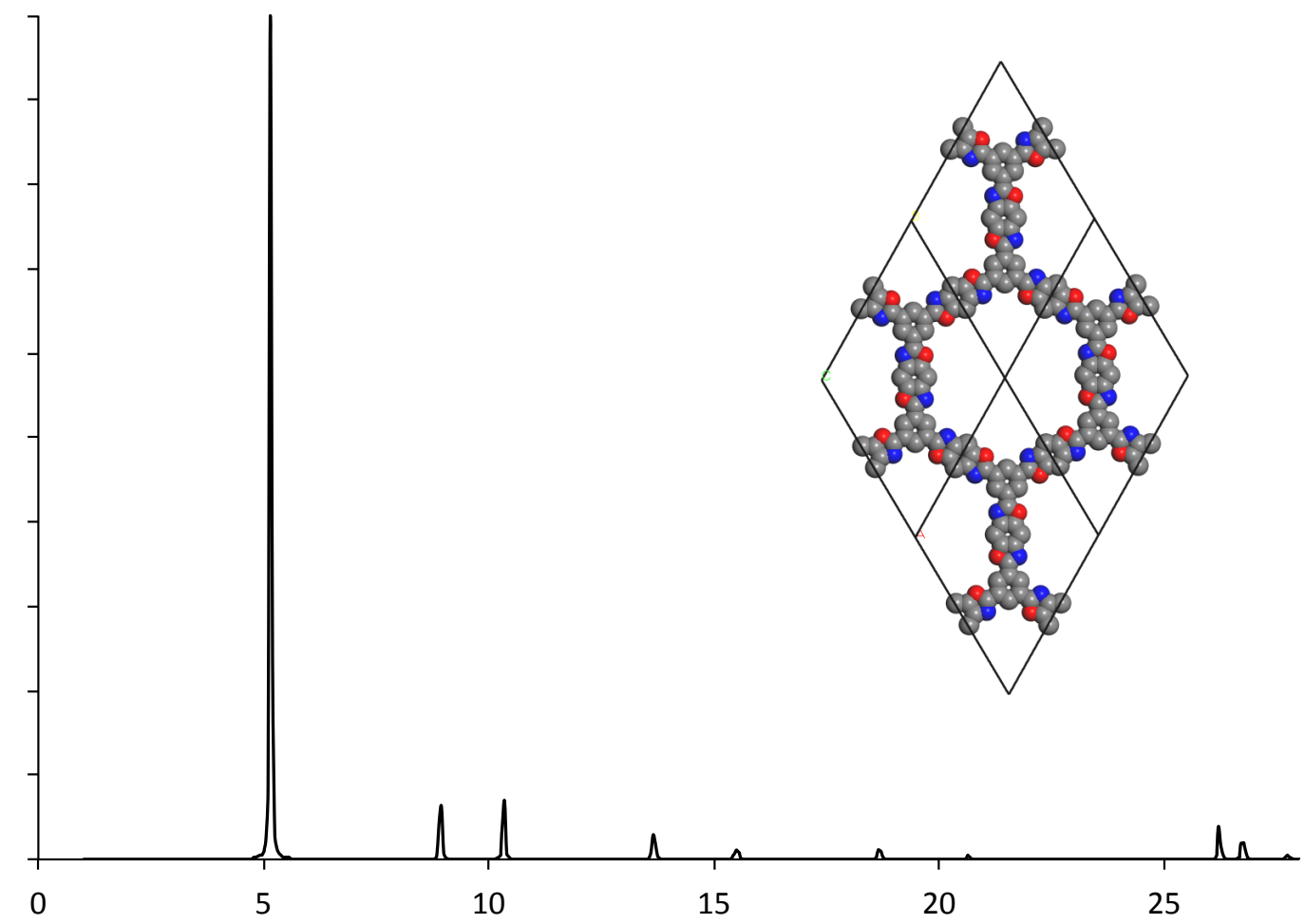

Figure S8. Simulated PXRD of BBO-COF 1 modeled using a bnn unit cell (top right). 


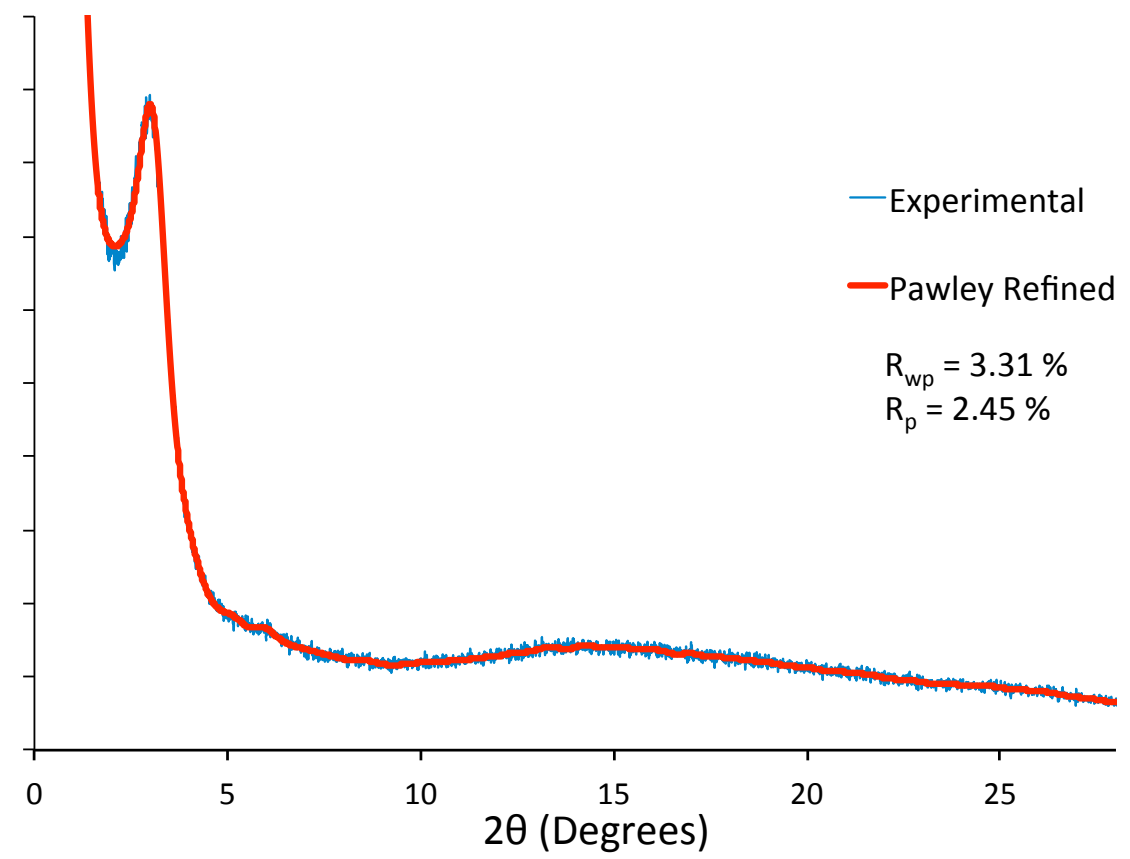

Figure S9. Experimental (red) and Pawley refined (blue) PXRD of BBO-COF 2.

Table S4. Fractional atomic coordinates for the bnn (P6/mmm) unit cell of BBO-COF 2 calculated using the Materials Studio 7.0.

\begin{tabular}{|cccc|}
\hline \multicolumn{5}{|c|}{ BBO-COF 2 } \\
\hline \multicolumn{4}{c|}{ Hexagonal, $P$ P s space group } \\
\hline Atom & $\mathbf{x}$ & $\mathbf{y} 5.796, \mathrm{C}=3.4$ \\
C1 & 0.548058 & 0.386988 & $\mathbf{z}$ \\
H2 & 0.511327 & 0.368644 & 0.0409835 \\
C3 & 0.569026 & 0.429334 & 0.050515 \\
C4 & 0.547173 & 0.452101 & 0.051432 \\
N5 & 0.507691 & 0.433757 & 0.049942 \\
C6 & 0.499471 & 0.465849 & 0.047246 \\
C7 & 0.461720 & 0.463649 & 0.047440 \\
H8 & 0.430948 & 0.430929 & 0.042325 \\
C9 & 0.463198 & 0.501073 & 0.051253 \\
O10 & 0.431105 & 0.508342 & 0.050035 \\
C11 & 0.451487 & 0.551281 & 0.055513 \\
C12 & 0.429546 & 0.573803 & 0.056426 \\
C13 & 0.387161 & 0.552610 & 0.051781 \\
H14 & 0.368860 & 0.515880 & 0.047044 \\
C15 & 0.366033 & 0.573720 & 0.052603 \\
\hline
\end{tabular}




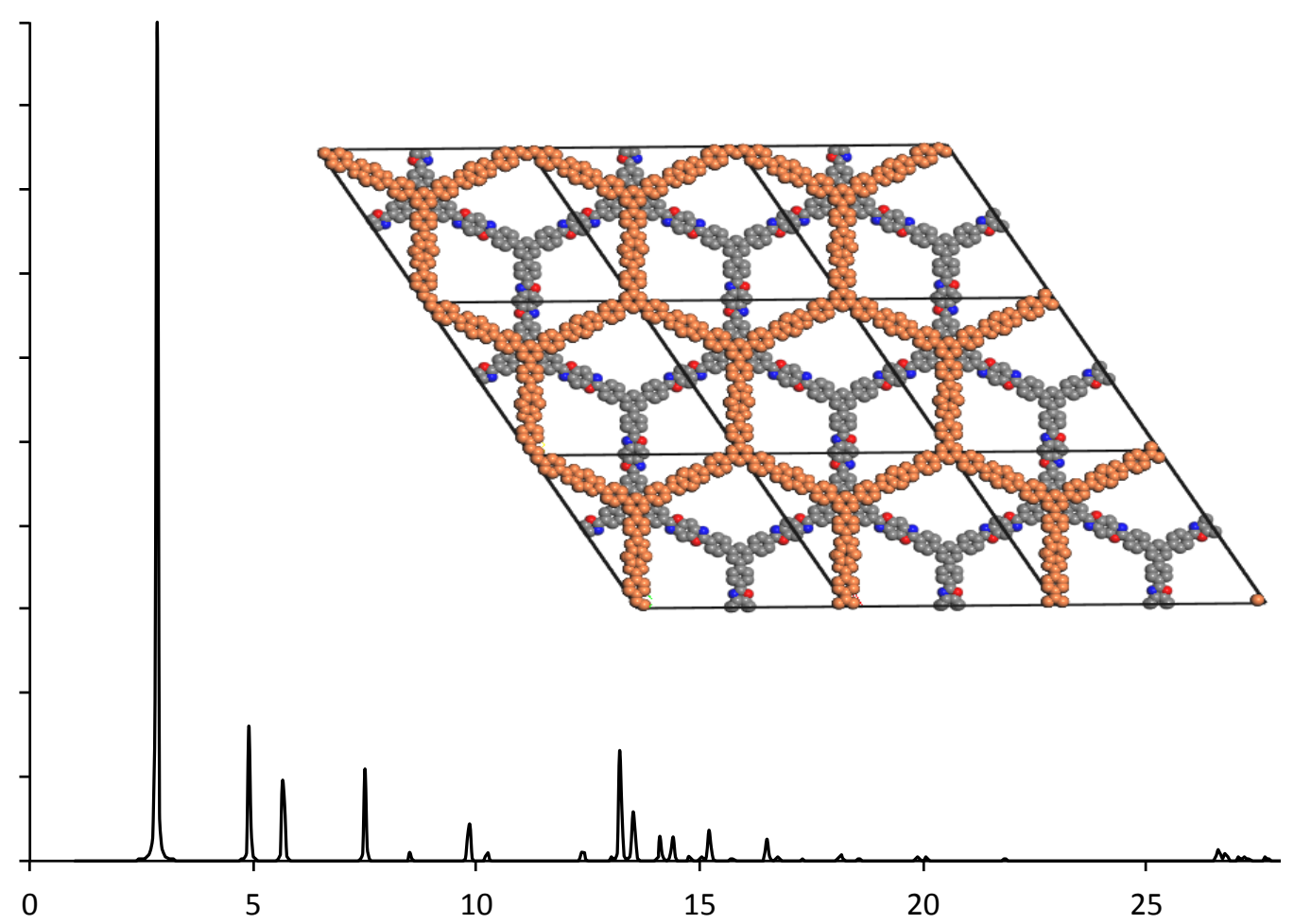

Figure S10. Simulated PXRD of BBO-COF 2 modeled using a gra unit cell (top right).

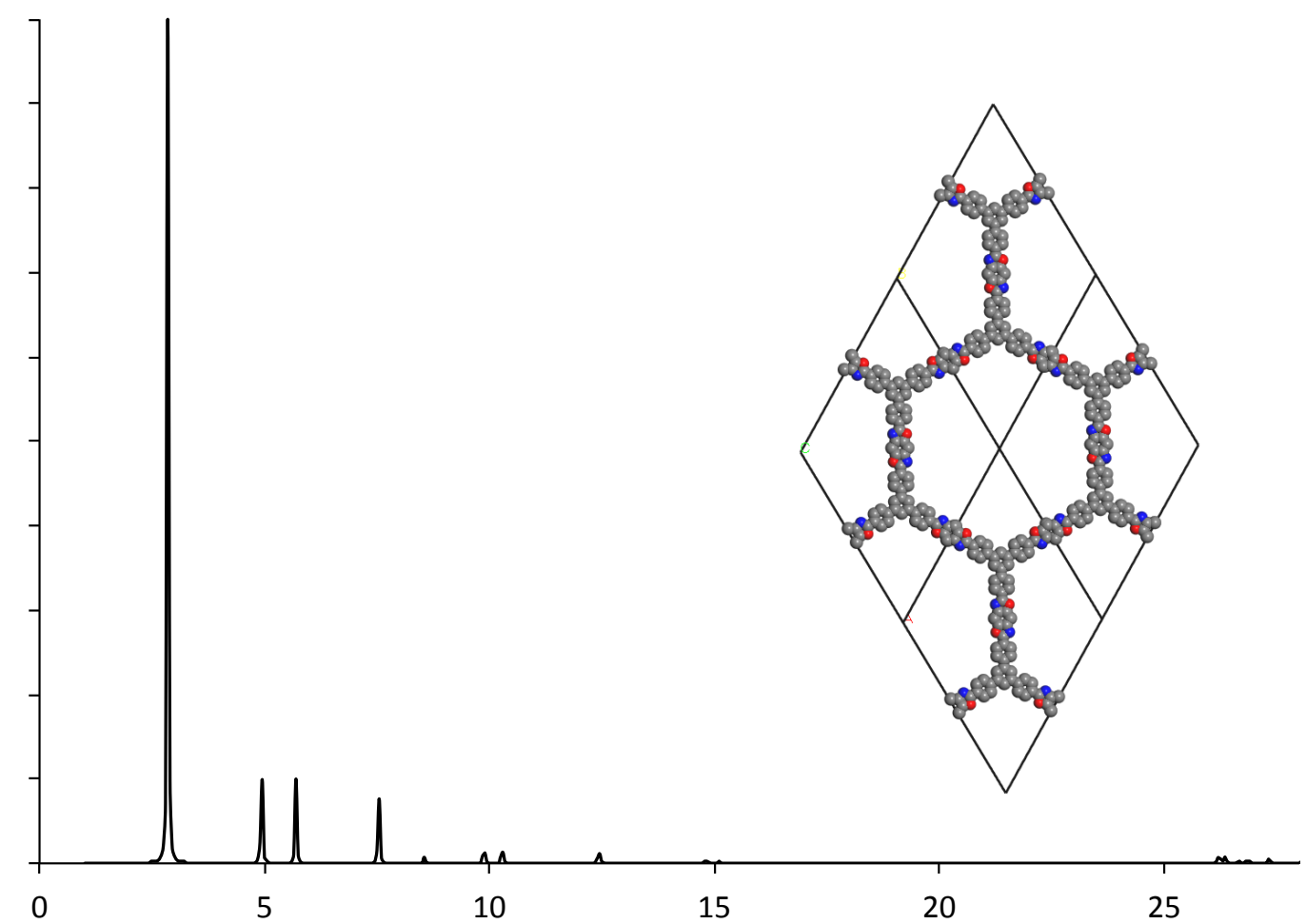

Figure S11. Simulated PXRD of BBO-COF 2 modeled using a bnn unit cell (top right). 


\section{F. Solid State NMR Spectra}
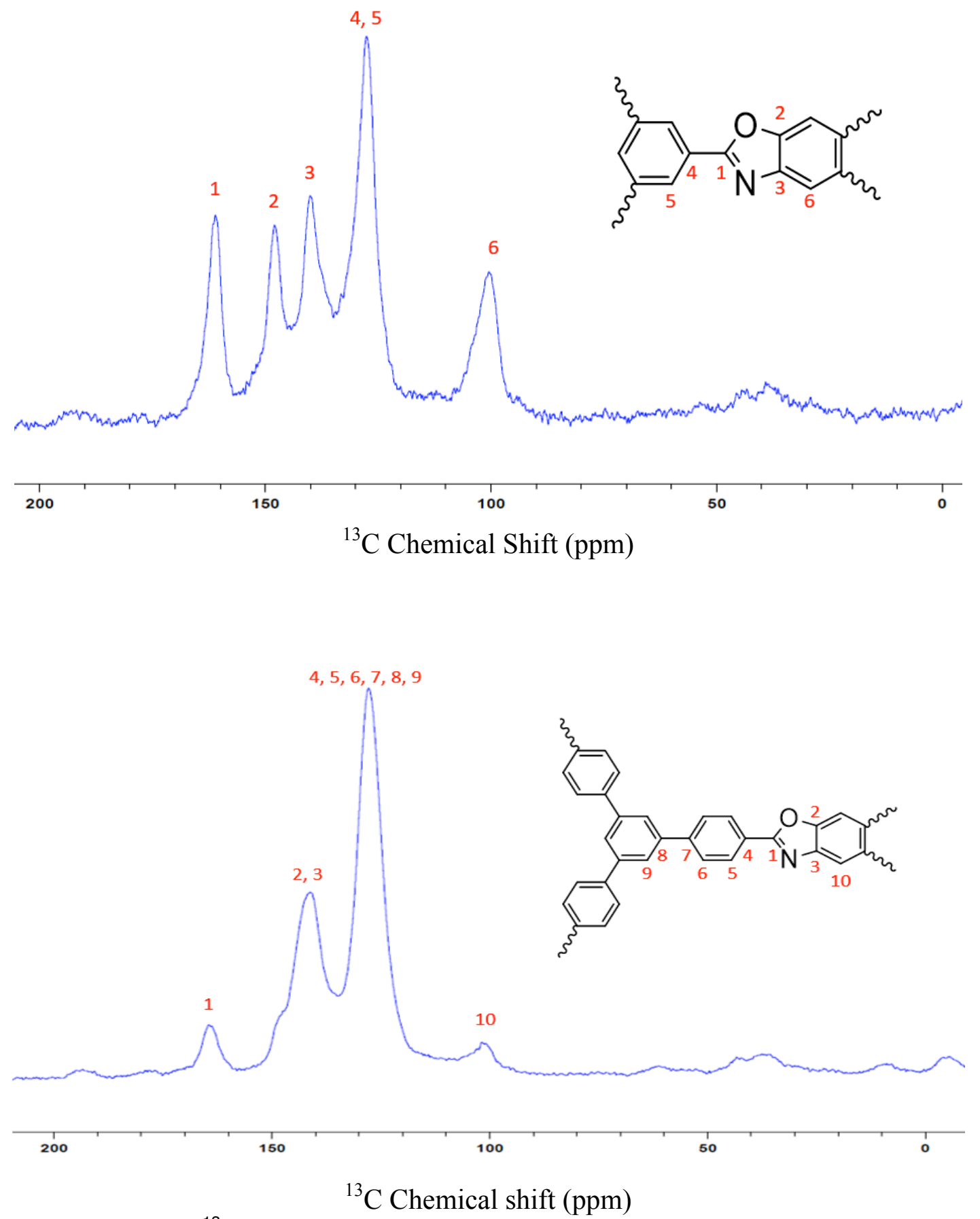

Figure S12. $75.5 \mathrm{MHz}{ }^{13} \mathrm{C}$ CP-MAS solid-state NMR spectra of BBO-COF 1 (top) and BBOCOF 2 (bottom). 


\section{G. TGA Profiles}

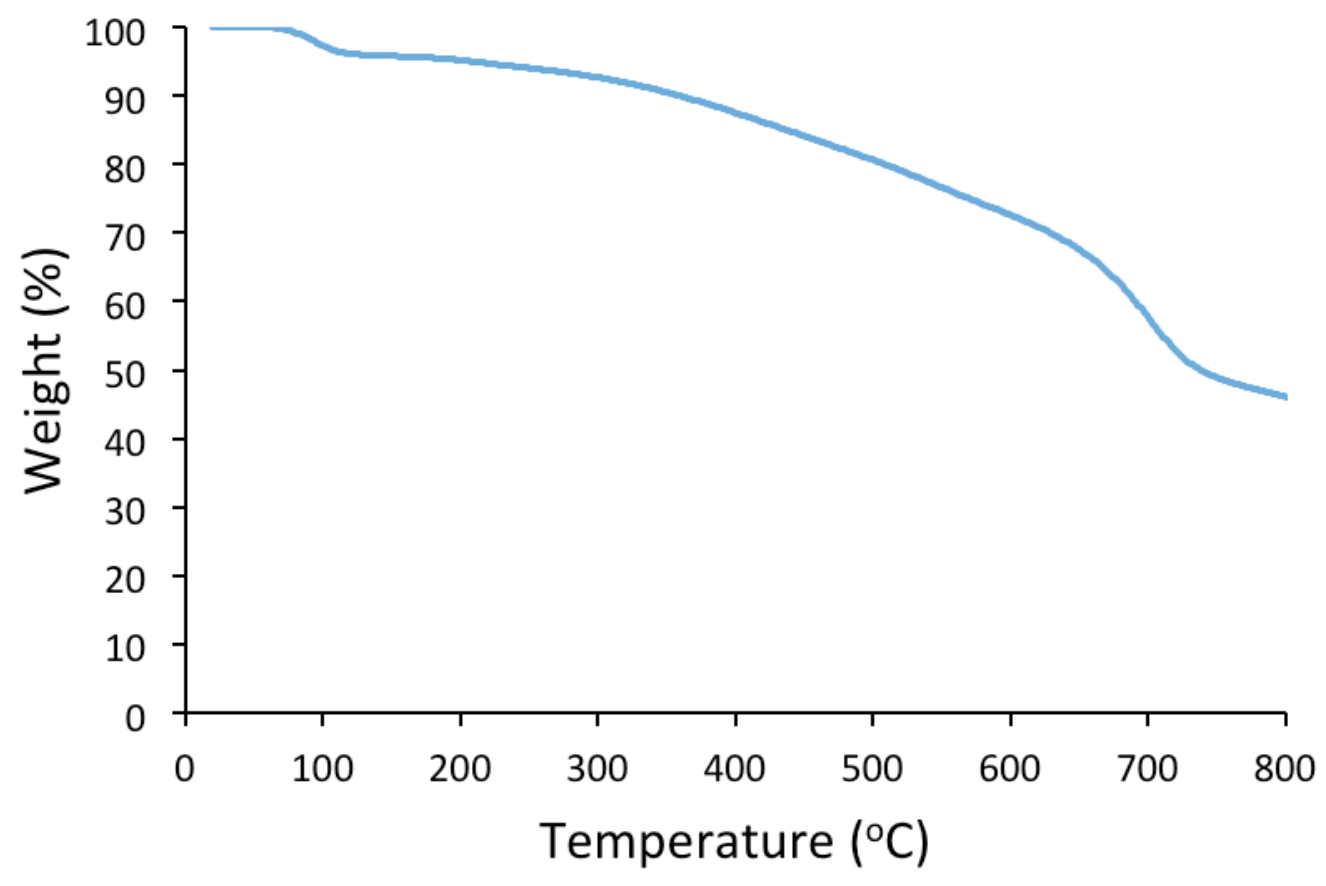

Figure S13. TGA plot of BBO-COF 1.

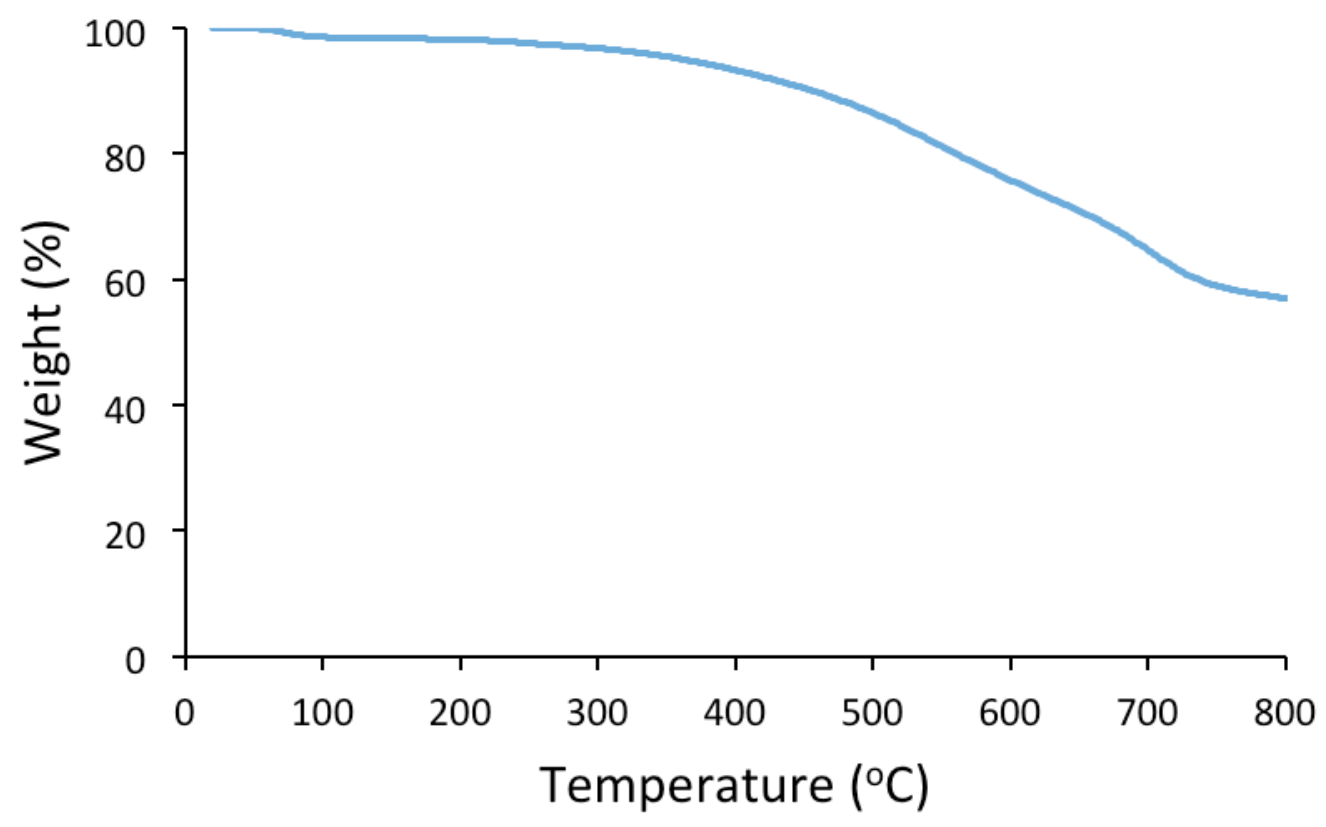

Figure S14. TGA plot of BBO-COF 2. 
H. BET Surface Area Plots \& Pore Volume Calculations

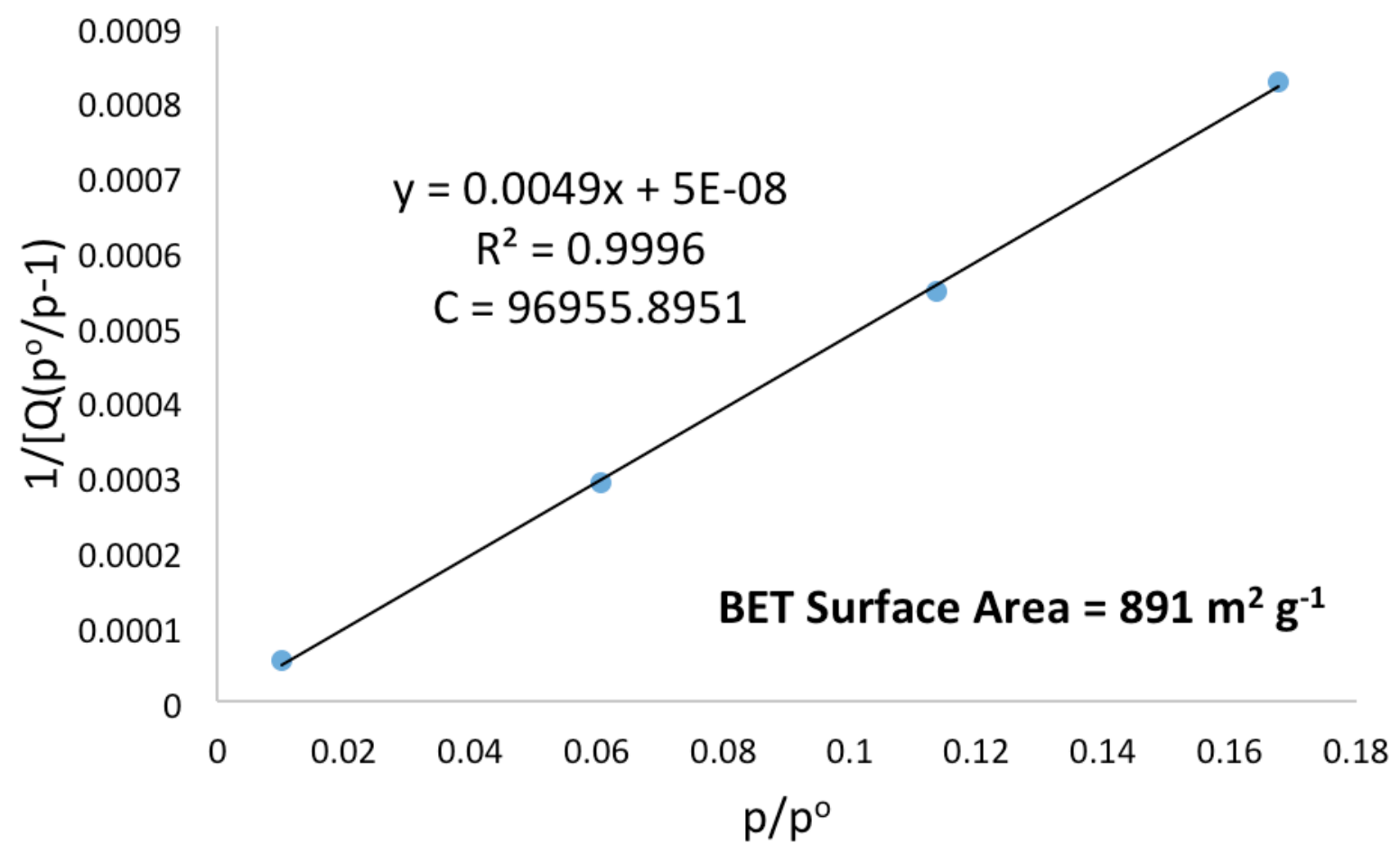

Figure S15. BET surface area plot for BBO-COF 1.

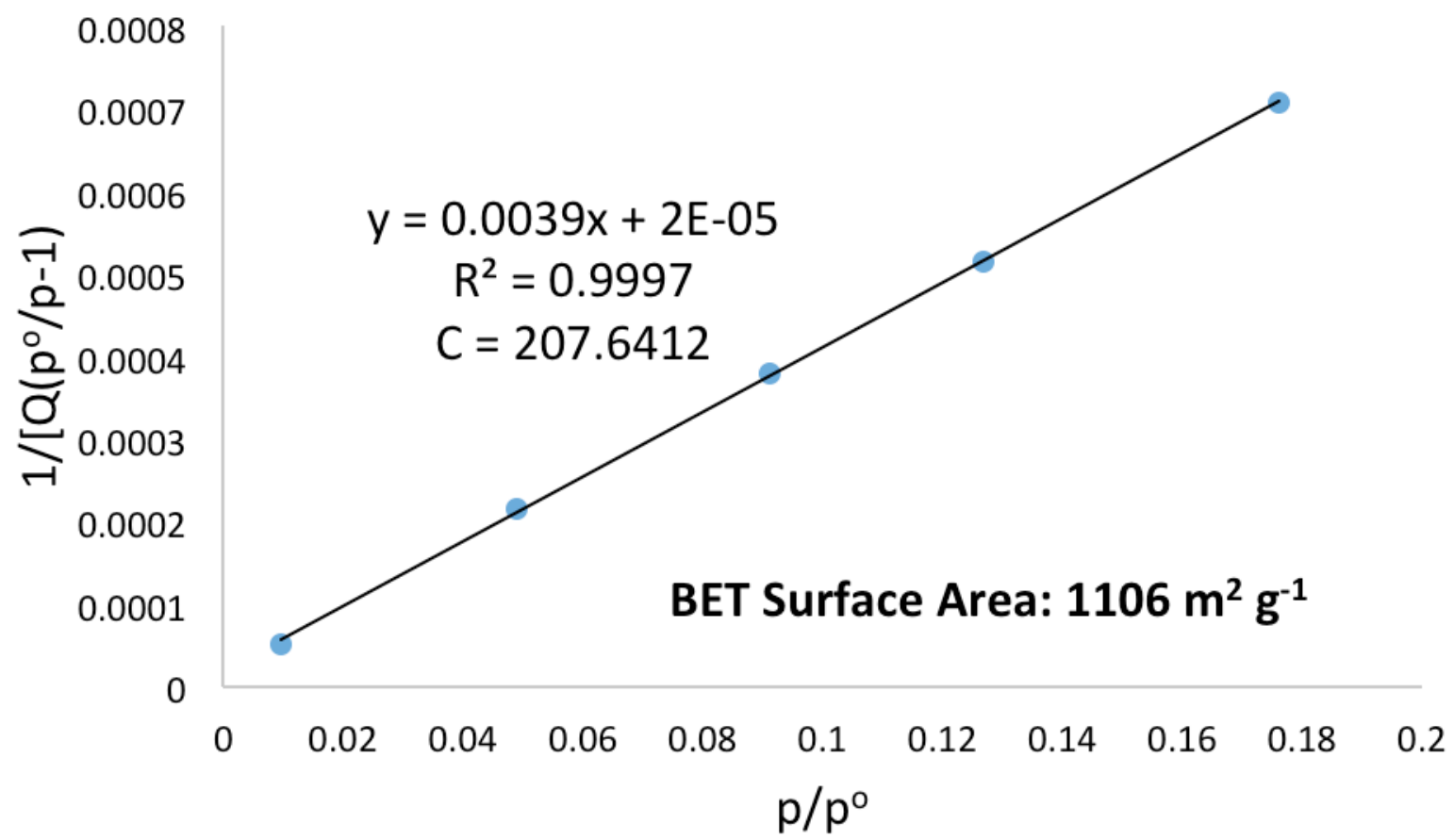

Figure S16. BET surface area plot for BBO-COF 2. 


\section{Isoteric Heats of Adsorption Plots}

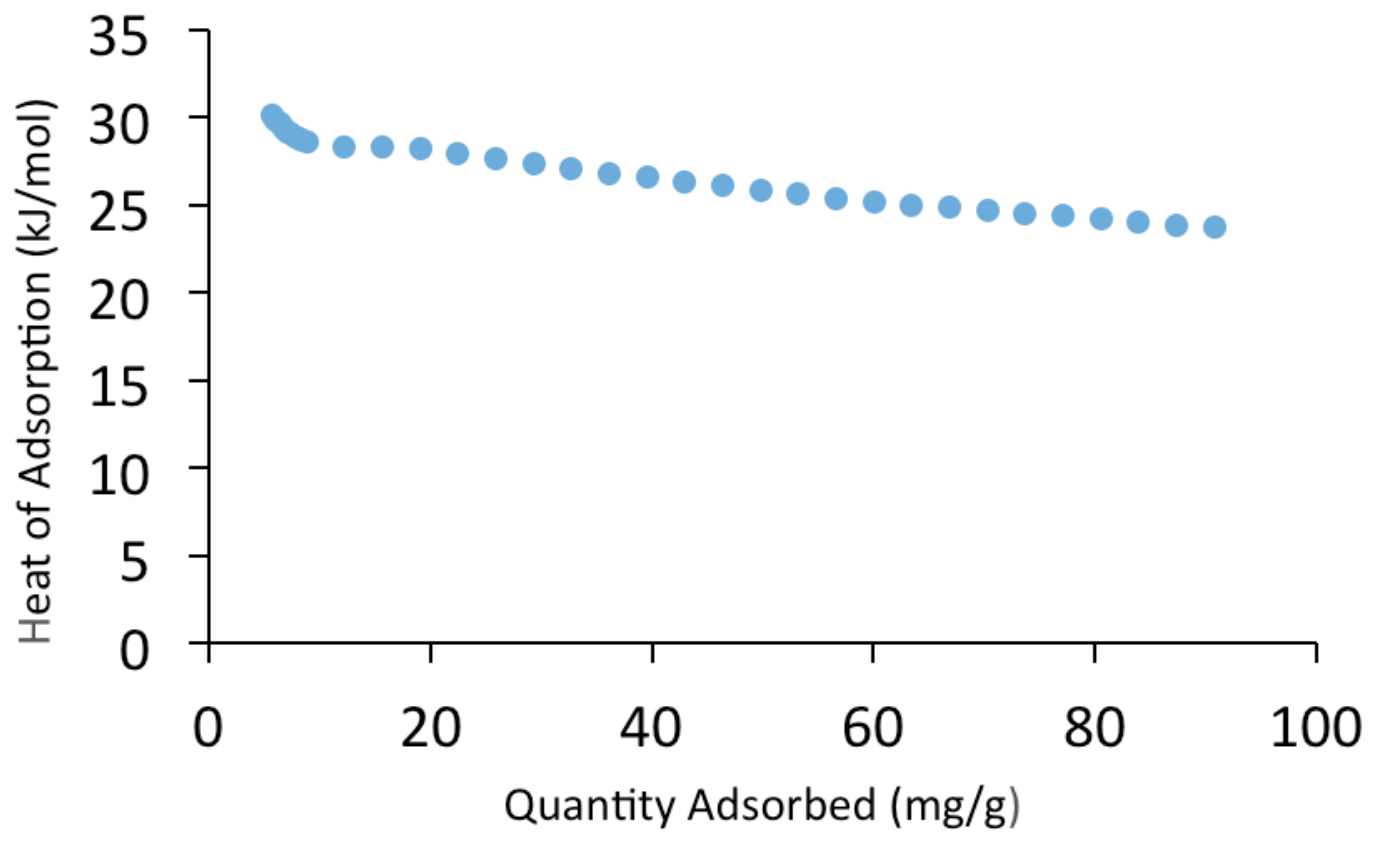

Figure S17. Isosteric heat of $\mathrm{CO}_{2}$ adsorption for $\mathrm{BBO}-\mathrm{COF} 1$.

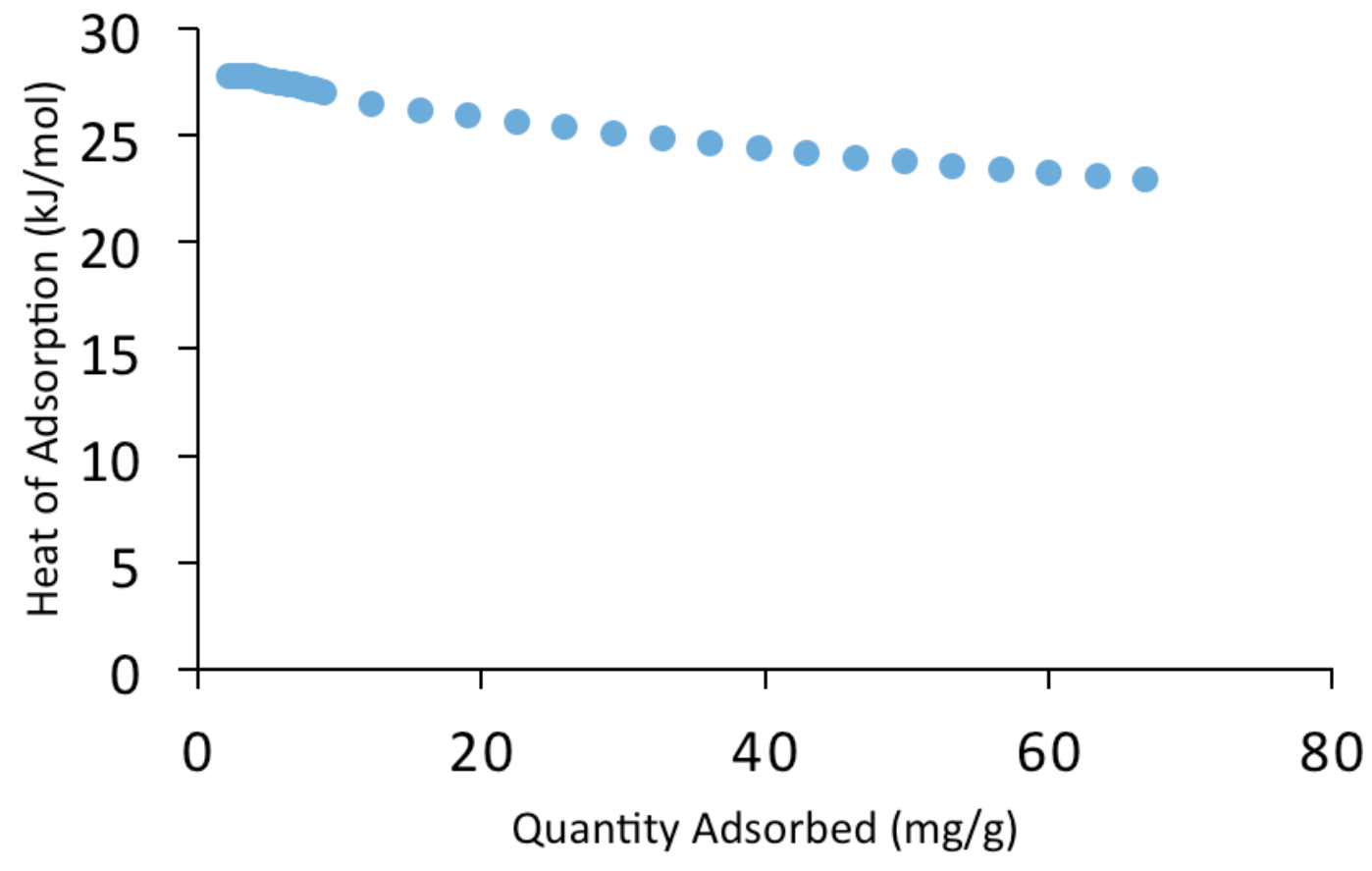

Figure S18. Isosteric heat of $\mathrm{CO}_{2}$ adsorption for BBO-COF 2. 


\section{J. $\mathrm{CO}_{2} / \mathrm{N}_{2}$ Selectivity Plots}

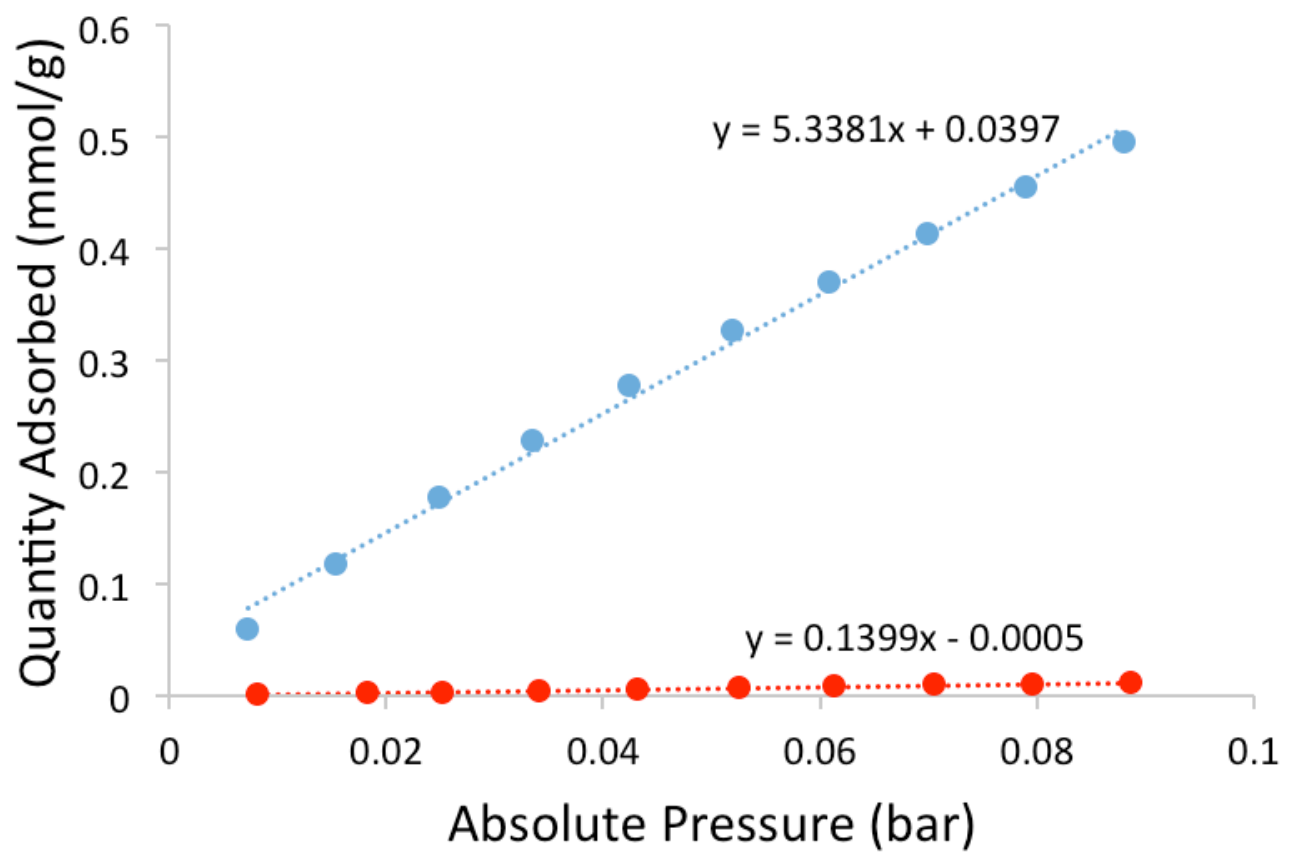

Figure S19. Initial slope measurements for BBO-COF 1 with $\mathrm{N}_{2}$ (red) and $\mathrm{CO}_{2}$ (blue) at $273 \mathrm{~K}$ resulting in a selectivity of 35.5 .

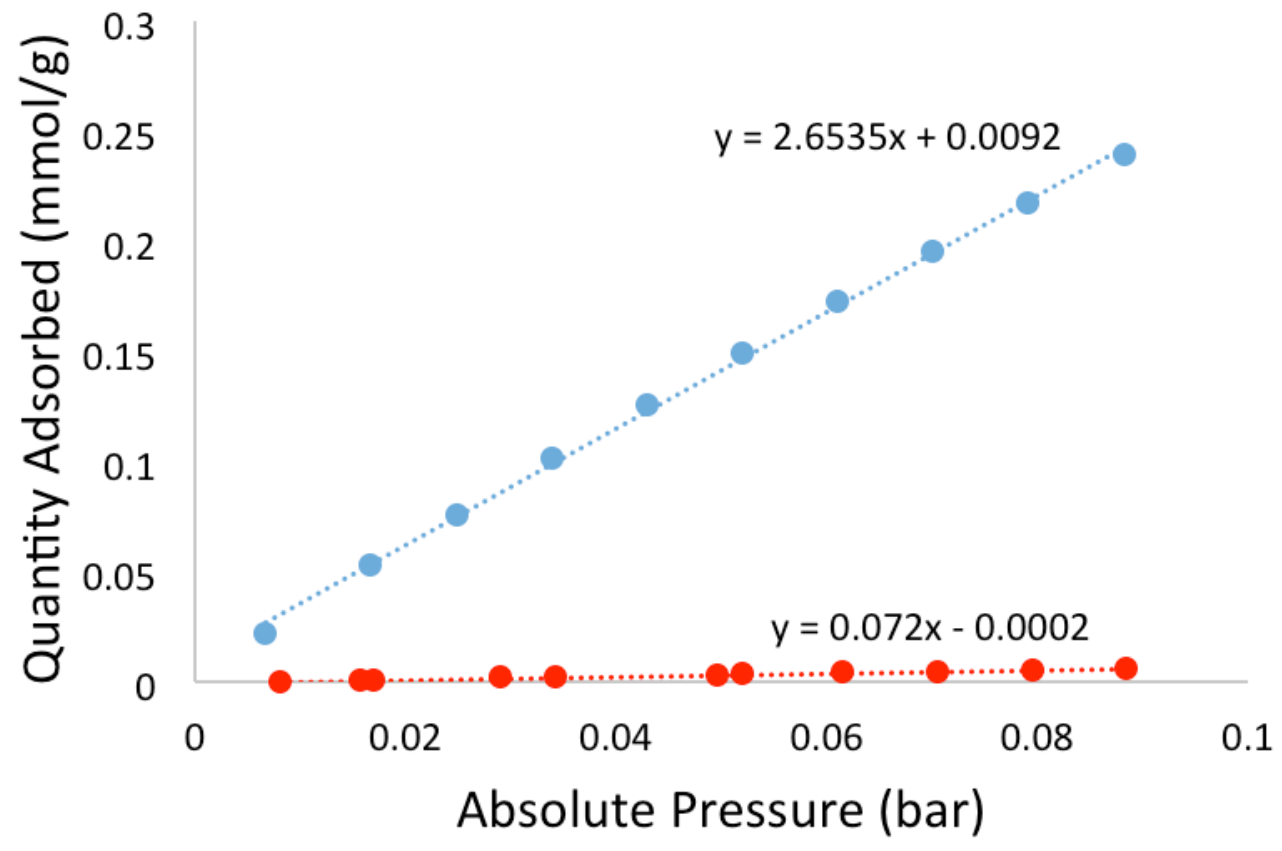

Figure S20. Initial slope measurements for BBO-COF 1 with $\mathrm{N}_{2}$ (red) and $\mathrm{CO}_{2}$ (blue) at $295 \mathrm{~K}$ resulting in a selectivity of 35 . 


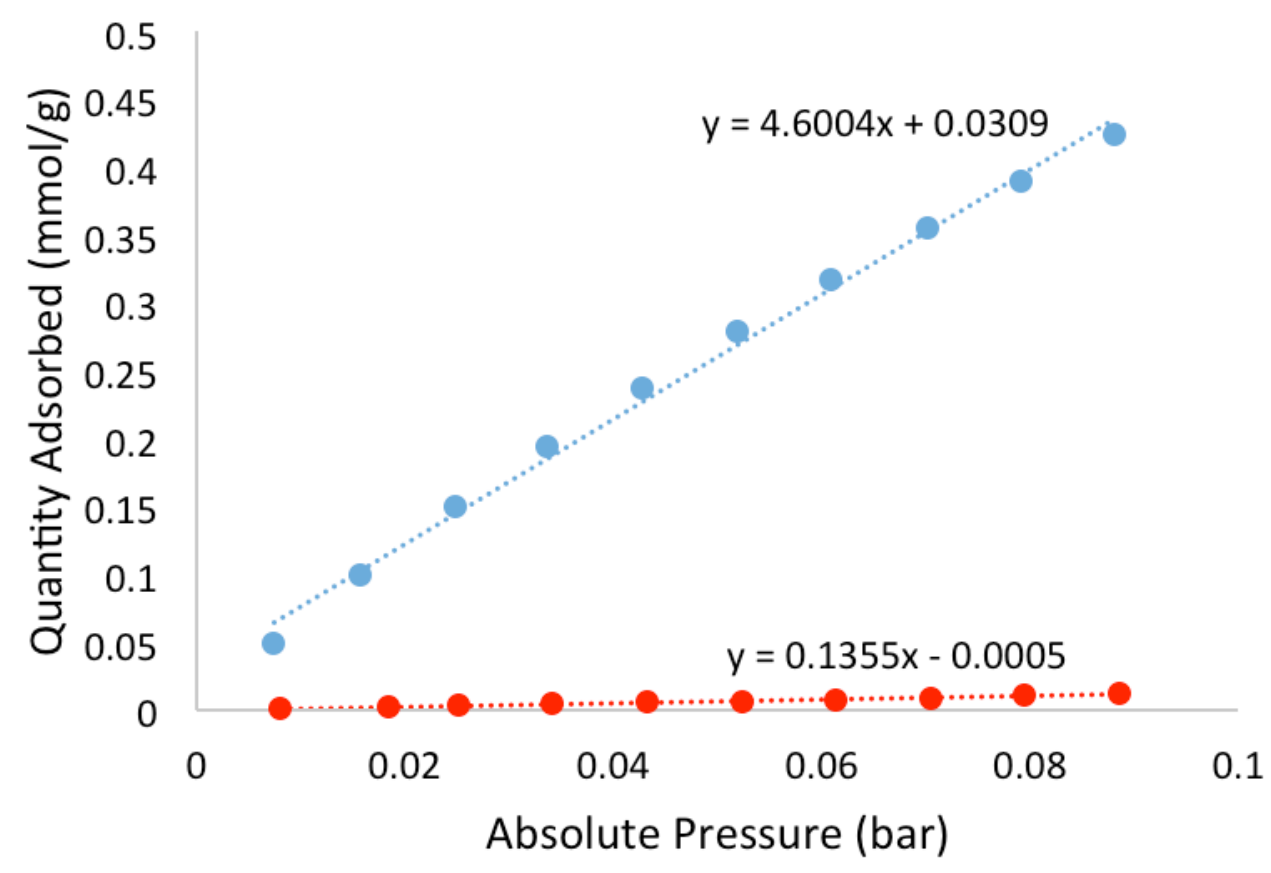

Figure S21. Initial slope measurements for BBO-COF 2 with $\mathrm{N}_{2}$ (red) and $\mathrm{CO}_{2}$ (blue) at $273 \mathrm{~K}$ resulting in a selectivity of 30.5 .

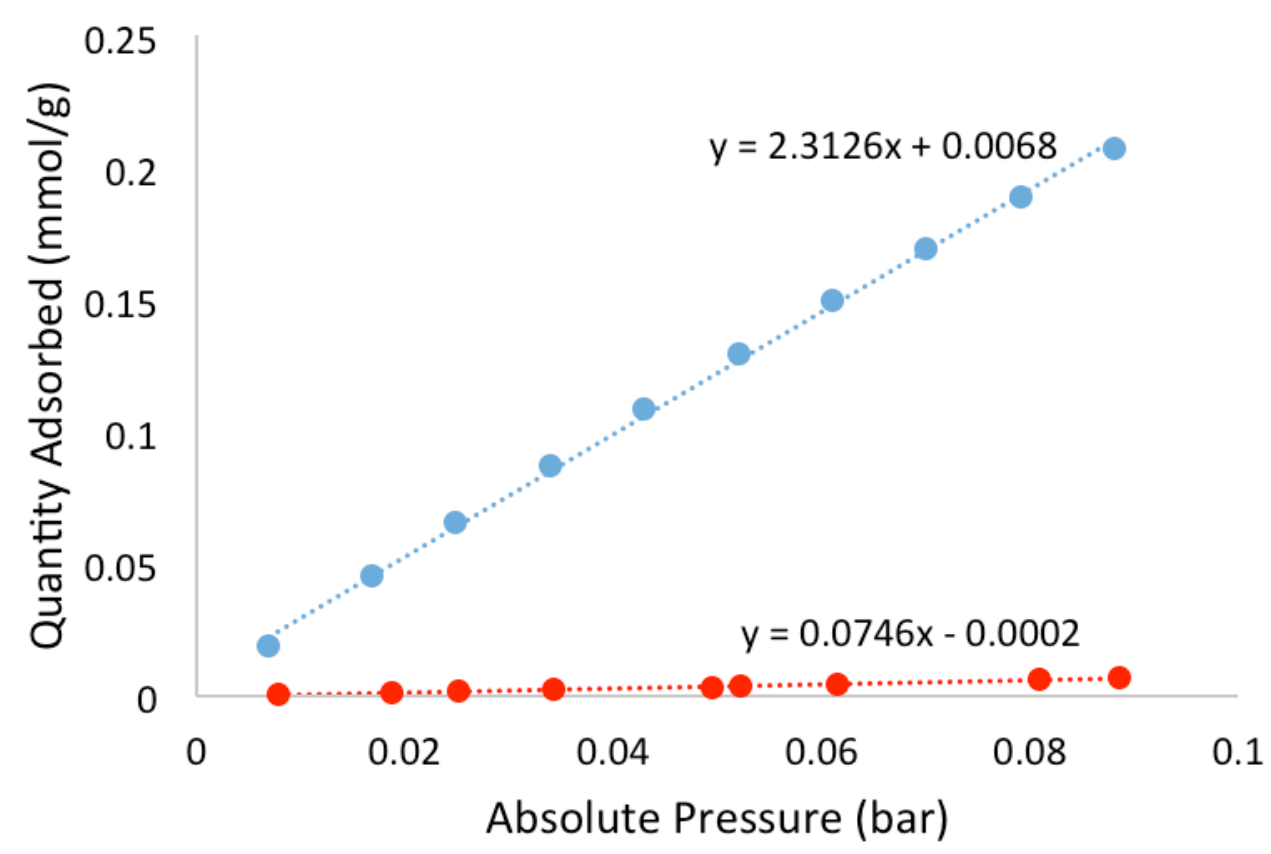

Figure S22. Initial slope measurements for BBO-COF 2 with $\mathrm{N}_{2}$ (red) and $\mathrm{CO}_{2}$ (blue) at $295 \mathrm{~K}$ resulting a selectivity of 31 . 


\section{K. SEM Micrographs}
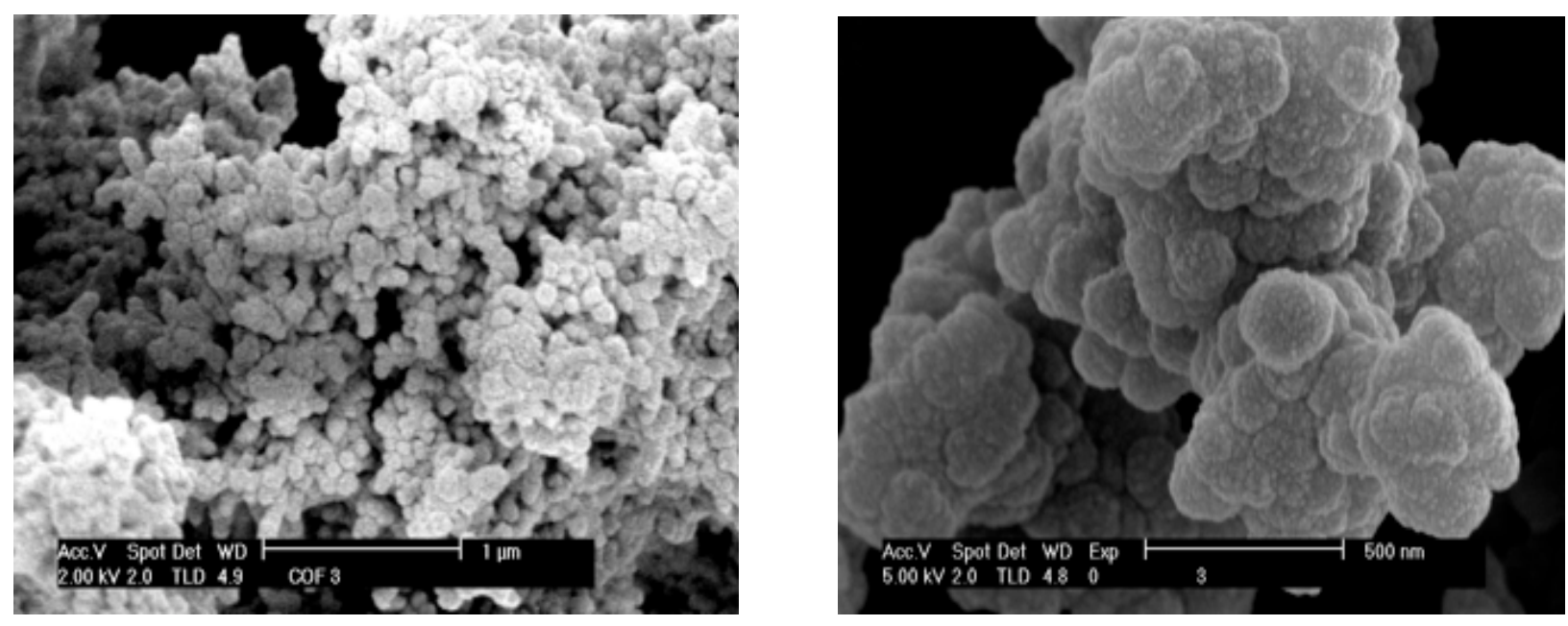

Figure S23. SEM Micrograph images for BBO-COF 1.
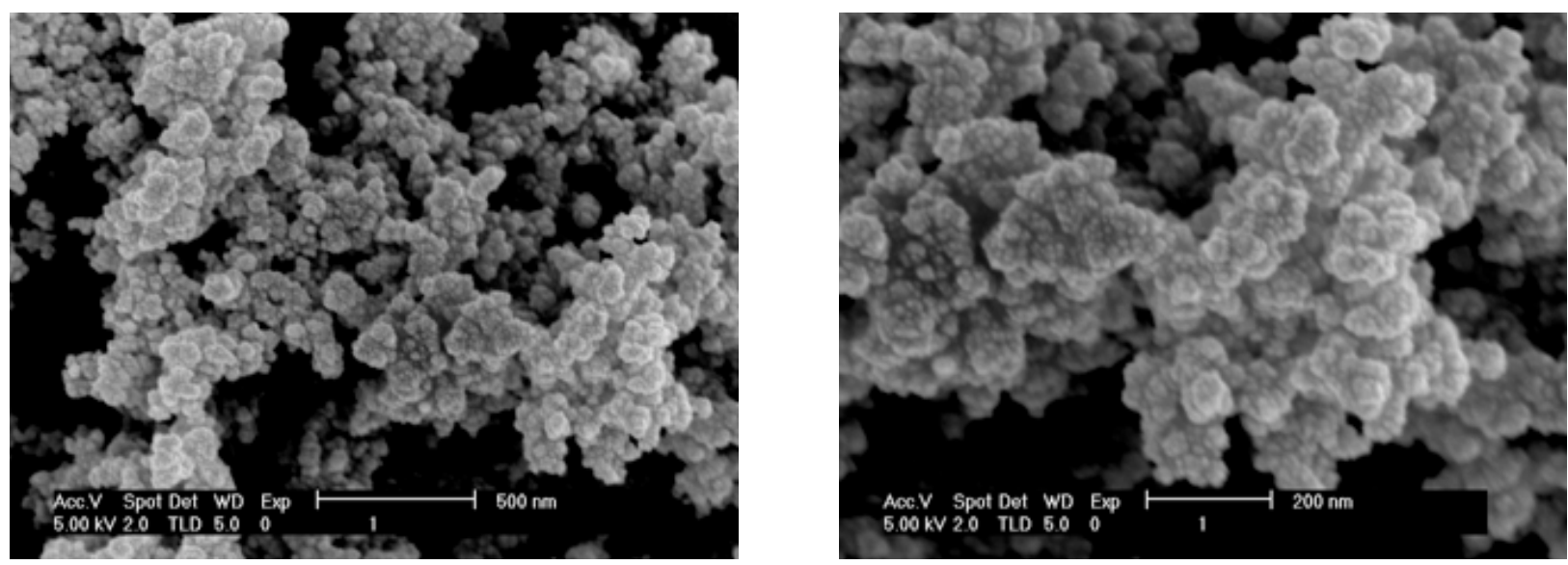

Figure S24. SEM Micrograph images for BBO-COF 2. 


\section{Water Stability Graph}

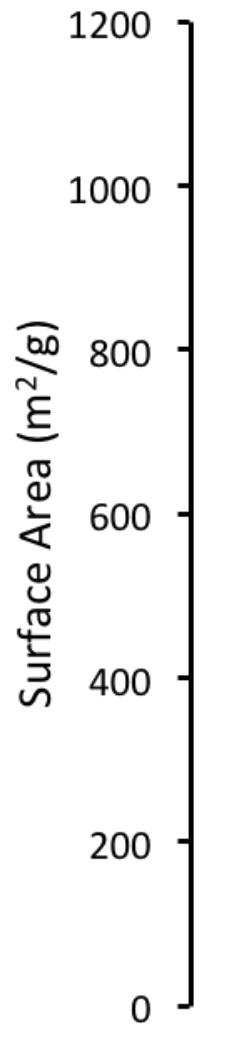

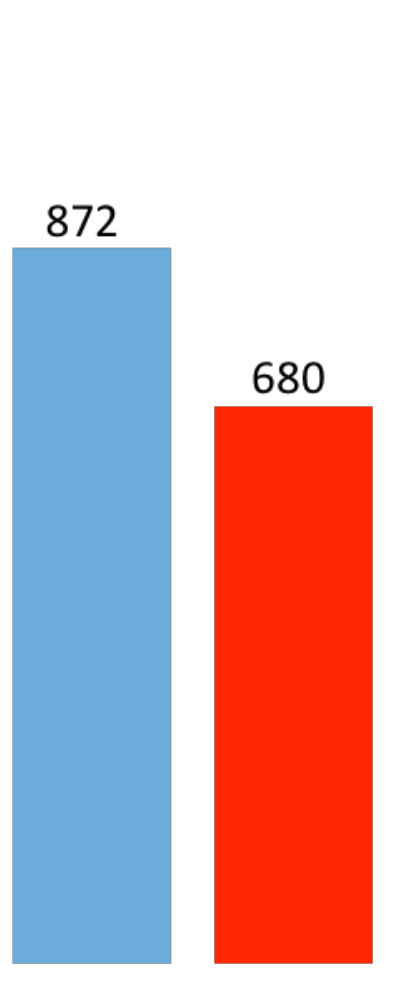

BBO-COF 1

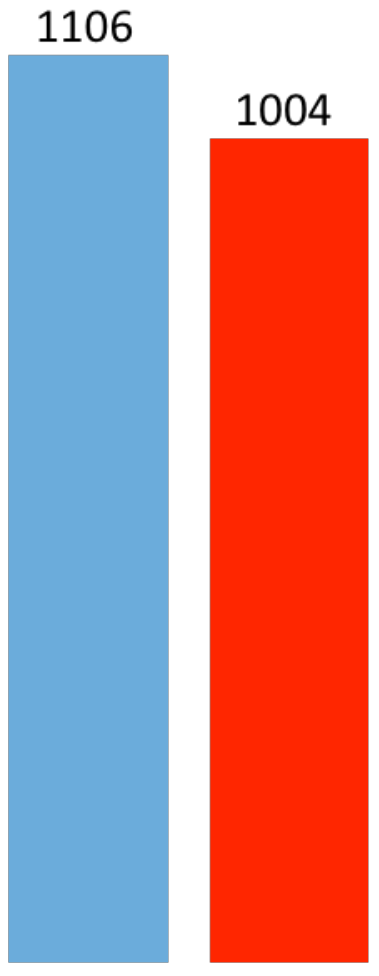

BBO-COF 2

Figure S25. Surface area measurements of BBO-COFs before (blue) and after (red) soaking in boiling water for 24 hours. The BBO-COFs were filtered and dried under vacuum and degased at $130{ }^{\circ} \mathrm{C}$ for 12 hours before the measurements were taken. 
M. ${ }^{1} \mathrm{H}$ and ${ }^{13} \mathrm{C}$ NMR Spectra of BBO-1
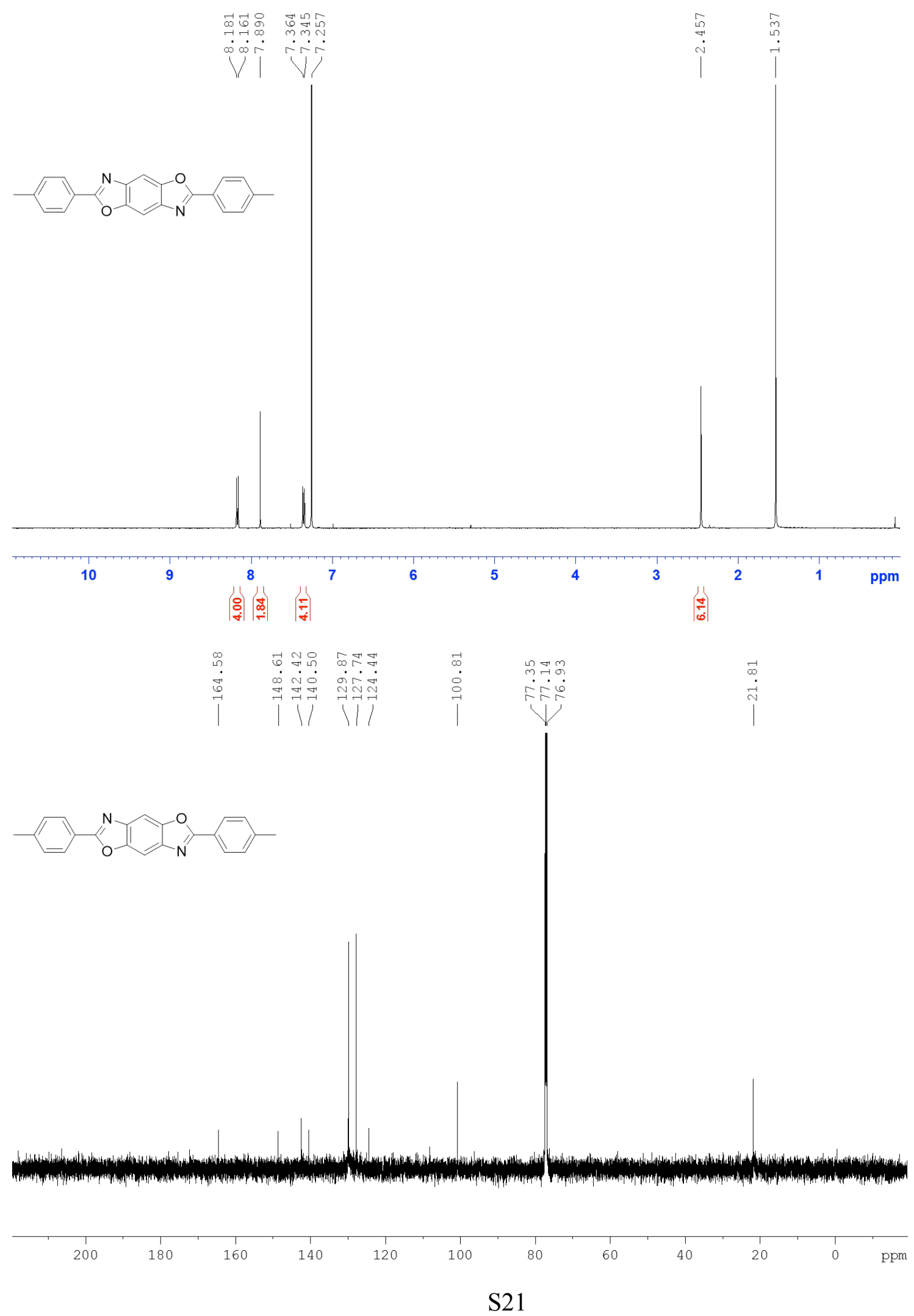


\section{References:}

1. M. Inbasekaran, R. Strom, A Convenient Synthesis of 2,5-Diamino-1,4-benzenediol. Org. Prep. Proced. Int. 1991, 23, 447-450.

2. J. F. Mike, A. J. Makowski, M. Jeffries-EL, An Efficient Synthesis of 2,6-Disubstitued Benzobisoxazoles: New Building Blocks for Organic Semiconductors. Org. Lett. 2008, 10, 4915-4918.

3. N. Kaur, J. Delcros, J. Imran, A. Khaled, M. Chehtane, N. Tschammer, B. Martin, O. Phanstiel IV, A comparison of Chloroambucil- and Xylene-Containing Polyamines Leads to Improved Ligands for Accessing the Polyamine Transport System. J. Med. Chem. 2008, 51, 1393-1401.

4. S. Jiang, J. Bacsa, X. Wu, J. Jones, R. Dawson, A. Trewin, D. J. Adams, A. I. Cooper, Selective Gas Sorption in a [2+3] 'Propeller' Cage Crystal. Chem. Commun. 2011, 47, 8919-8921. 